\author{
EDWARD M. GRAMLICH* \\ Brookings Institution
}

HARVEY GALPER*

Urban Institute

\title{
State and Local Fiscal Behavior and Federal Grant Policy
}

Purchases by STATE AND LOCAL Governments have long been the most rapidly rising component of aggregate demand. While real consumption and investment expenditures have both doubled since the end of the Korean war, and federal purchases have increased barely at all, state and local purchases of goods and services have almost tripled. They have grown at an annual average rate of 5.5 percent and now account for over 10 percent of real gross national product (GNP).

For much of this period, the budgetary surplus for state and local governments hovered very close to zero, being negative as often as positive and never amounting to more than $\$ 2$ billion. Recently, however, the surplus has grown at a remarkable rate. It was only $\$ 0.7$ billion as late as

* We have benefited from the comments of several members of the Brookings panel, and also from discussions with Frank de Leeuw, Robert W. Hartman, Larry L. Orr, George E. Peterson, and Robert D. Reischauer. Charles A. Waite has supplied us with unpublished national income accounts data, Joseph Valenza ably assisted with the computer work, Su Nokkeo with data preparation, and Kathryn Breen and Patricia Sachs with the typing. Some of the results in the paper are taken from an Urban Institute study, financed by the Office of Economic Opportunity, on the distributional aspects of urban fiscal behavior. A preliminary report on this project can be found in Harvey Galper, Edward Gramlich, Claudia Scott, and Hartojo Wignjowijoto, "A Model of Central City Fiscal Behavior," forthcoming in the Proceedings of the 28th Congress of the International Institute of Public Finance, 1972. 
1969 but then began a rapid expansion, reaching $\$ 4.8$ billion in 1971 and $\$ 12.3$ billion in 1972-when it attained an annual rate of almost $\$ 20$ billion in the fourth quarter. Though special factors have accounted for some of this rise, a 1972 report on the fiscal policies of President Nixon and Senator George McGovern predicted that the state and local surplus would rise even higher under both sets of proposals. ${ }^{1}$

Grants to state and local governments from the federal government were undoubtedly responsible for much of the increase in expenditures, and possibly the budget surplus as well. Whereas in 1954 these grants amounted to only $\$ 2.9$ billion, by 1974 they are expected to reach $\$ 41.6$ billion, a thirteen-fold expansion. ${ }^{2}$ And grants are of current interest not only because of their sheer growth. The recent enactment of general revenue sharing, the administration proposal to convert existing categorical grants to special revenue sharing, and numerous other plans to federalize welfare payments or to provide property tax relief or income tax credits to state and local taxpayers-all indicate that fundamental changes are occurring in the form of federal assistance to states and localities.

The increasing importance of the state and local sector and the changing role of federal grants point to the need for a more thorough understanding of the budgetary behavior of state and local governments, particularly the way in which it is influenced by intergovernmental transfers. To explore this topic, we first estimate a model of state and local fiscal behavior and then use it to examine these policy questions.

We begin by discussing different forms of grant assistance and how they might be expected to affect the budgetary behavior of states and localities differently. These ideas underlie our theory of state and local fiscal behavior, from which we derive a consistent set of estimating equations for state and local expenditures, revenues, and the budget surplus. The independent variables in these equations are federal grants of various types, income, relative prices, previous stocks of financial assets, and demographic variables.

The model is estimated with two separate bodies of data: (1) quarterly time series observations on the entire state and local sector in the national income accounts for the period 1954-72; (2) annual budgetary observations for a sample of ten urban governments for the period 1962-70. While

1. See David J. Ott and others, Nixon, McGovern, and the Federal Budget (Washington: American Enterprise Institute for Public Policy Research, 1972).

2. Special Analyses, Budget of the United States Government, Fiscal Year 1974, p. 8. 
the coverage of the time series sample is more comprehensive, the pooled cross-section data contain information on a wider range of intergovernmental assistance that is more finely disaggregated by function, and therefore helps to sharpen the estimates for certain critical parameters. These empirical results are then used to judge how the state and local sector responds to federal aid of various sorts, especially general and special revenue sharing, and to interpret the recent spectacular increases of the state and local budget surplus.

\section{Federal Grants}

Although there is a relatively well-developed theory of the roles played by different types of intergovernmental transfers, most empirical studies in this area have paid little attention to it. They have usually assumed that grants of whatever kind affected state and local government behavior in much the same way, disregarding a theory that postulated they would not. This approach may have yielded acceptable predictions of the growth of state-local spending as long as grants increased in volume without changing in structure, but it is clearly inappropriate now when grant policy is undergoing such a radical restructuring.

The theory of intergovernmental transfers suggests that grants from higher to lower levels of government can be classified into three broad types.

Case A. Open-end matching grants, under which the higher level of government pays some portion of the cost of certain state or local expenditures, thus effectively reducing their price, and the lower government is free to take as much of the grant money as it wants at this new price ratio. Federal grants of this type have all been in the welfare area-for public assistance, Medicaid, and social services. The response of expenditures by lower governments to these grants depends on the price elasticity of demand for the relevant good or service: The lower level of government increases total spending (from its own resources plus the grant) by more than the grant-and reduces it on all other goods-if demand is elastic, and increases spending by less than the grant-and raises it on all other goodsif demand is inelastic.

Case B. Closed-end lump-sum transfers, under which the higher level of government merely transfers a fixed amount of money to a lower gov- 
ernment without any effective restrictions on its use or any change in relative prices. The recently enacted general revenue-sharing program constitutes the first important federal policy of this type, though such programs have existed on the state level. The response of expenditures to these grants depends simply on the lower government's propensity to spend budgetary resources rather than to reduce taxes or add to its surplus. In the normal case, in which both public and private goods have positive income elasticities, lump-sum transfers will stimulate some increased public spending and some tax reduction. Case B grants will also stimulate less total spending per dollar of grant than case A grants if the demand for expenditures is at all sensitive to price changes.

Case C. Closed-end categorical grants, through which the higher level of government transfers a limited amount of money to be used for a specific program. These grants are a hybrid of case A and B grants in that the higher government lowers the price of the aided activity but limits the size of the grant. All important grant programs at the federal level except those already noted have been of this type. Without any other restrictions, case $\mathrm{C}$ grants can be shown to have expenditure effects somewhere between those of case A and case B grants-less than open-end matching grants because the limitation on funds diminishes the impact of the price reduction, and more than lump-sum transfers because at least some price reduction occurs for the specified activity. If limited to incremental expenditures above some base amount, however, case $\mathrm{C}$ categorical grants can increase expenditures by more than open-end case A grants that are not subject to such restrictions. ${ }^{3}$

These straightforward ideas become difficult to apply once diverse types of expenditures are aggregated into functional categories for empirical study. For any one type of expenditure, open-end case A grants will stimulate more spending per dollar of grant than closed-end categorical case $\mathrm{C}$ grants without other restrictions, which themselves stimulate more expenditures than lump-sum $\mathrm{B}$ transfers. But case $\mathrm{C}$ grants could be observed to have a larger impact per dollar on spending than case A grants if existing $\mathrm{C}$ grant programs make more use of effort maintenance requirements that confine aid to incremental expenditures in a certain category, or if $\mathrm{C}$ grants have been more extensively used to support activities that have not

3. These propositions are described more completely in James A. Wilde, "Grantsin-Aid: The Analytics of Design and Response," National Tax Journal, Vol. 24 (June 1971), pp. 143-55. 
previously been carried out at the state-local level and are therefore incremental expenditures in effect. The situation is complicated even further because grants have different legal and administrative provisions, and because they go to many different lower governments, special districts, and the like, all with presumably different behavioral responses.

Recognizing that we cannot deal with all of these complexities, we have nevertheless tried to estimate the differing responses to various types of grants, first on an aggregate basis and then with some disaggregation. Our approach is to classify grants into the three types on the basis of information about the nature of the program, then to enter these grants as independent variables in regressions in order to estimate their separate effects. This approach allows us to determine how state and local governments might respond to different types of grants and to changes in the restrictions accompanying them. ${ }^{4}$

In our model, case A open-end matching grants are assumed to reduce the price of the grant-aided goods and services by the fraction $\left(1-M_{A}\right)$, where $M_{A}$ represents the federal share of total expenditures in the category and is the exogenous policy instrument. The dollar volume of transfers of the case $\mathrm{B}$ type, $B$, are simply added to the budgetary resources at the command of state and local governments; the size of the grant is then the exogenous variable. With categorical case $\mathrm{C}$ grants, the lower level of government is assumed to take the entire grant available $(C)$ and this amount, along with the matching rate $\left(M_{C}\right)$, is used as the exogenous policy instrument to determine the volume of "mandated" expenditures on the good or service supported by the grant, $C / M_{C}$. This would be the level of spending for this activity required of the lower government in order to obtain the federal grant. Then the recipient government is assumed, in response to the mandated spending, to reduce its other "discretionary" expenditures on these programs-the amount it was spending in excess of $C / M_{C}$. The degree to which lower governments reduce discretionary spending, which we will term the grant displacement effect, determines the location of the impact of case $\mathrm{C}$ grants between case $\mathrm{A}$ and $\mathrm{B}$ grants. If grant displacement

4. In first classifying grants and then estimating their separate effects, our approach differs from that of Martin McGuire, who takes all grants together and estimates the degree to which they reduce prices or increase income. See his "Federal-Local Interactions in the Allocation of Resources" (University of Maryland, Department of Economics, 1972; processed). Since we place no restrictions on the relative responses to different types of grants, our treatment could lead to similar results, though within a framework that permits analysis of the response to changes in grant provisions. 
is complete, so that the federal government is simply paying for part of what states and localities would have done anyway, categorical $\mathrm{C}$ grants are identical to lump-sum B transfers, and our estimates will reflect this equivalence. If grant displacement is incomplete, $\mathrm{C}$ grants will have larger effects on total spending than B grants, and possibly even larger effects than A grants when the effective degree of effort maintenance in the $\mathrm{C}$ grant programs is high enough.

\section{A Model of the Determination of State and Local Expenditures, Revenues, and Budget Surplus}

These ideas about federal grants can be used to develop a model of the determination of state and local government expenditures, revenues, and budget surplus. The model incorporates an optimization procedure for the decision makers at the state-local level that parallels that used in the development of consumer demand functions for households. We first describe the objectives state and local officials seek in their budgetary policy, and then introduce the budget constraint that limits the attainment of these objectives. Maximizing the preference function subject to the budget constraint leads to a system of equations determining expenditures, revenues, and the budget surplus. ${ }^{5}$ The budget constraint ensures that an increase in expenditures must be financed by a grant, a rise in taxes, or a decline in the surplus. Similarly, the equations ensure that exogenous budgetary resources such as grants are completely allocated to all competing uses of funds.

\section{THE OBJECTIVES OF STATE AND LOCAL BUDGETARY POLICY}

We assume that state and local government budgetary policy has four main objectives: (1) higher current expenditures, whether locally initiated or resulting from the need to match federal case $\mathrm{C}$ grants; (2) higher private

5. This use of a maximization theory for state and local governments is similar to other recent contributions. See James M. Henderson, "Local Government Expenditures: A Social Welfare Analysis," Review of Economics and Statistics, Vol. 50 (May 1968), pp. 156-63; Robert P. Inman, "Four Essays on Fiscal Federalism" (Ph.D. thesis, Harvard University, 1971); Thomas E. Borcherding and Robert T. Deacon, "The Demand for the Services of Non-Federal Governments," American Economic Review, Vol. 62 (December 1972), pp. 891-901. 
disposable incomes, resulting from either higher pretax incomes or lower state and local taxes; (3) greater flows of services from the stock of tangible capital possessed by states and localities; (4) greater flows of services from the stock of net financial assets.

Current expenditures. Decision makers at the state-local level, whether they be government officials or, by virtue of their voting power, private households, are assumed to gain satisfaction both from expenditures mandated by federal categorical grants and from locally initiated discretionary expenditures. Total expenditures (purchases plus transfer payments) can be defined as the sum of mandated and discretionary expenditures through the identity,

$$
E X P=E+E_{M} .
$$

Here $E X P$ is total state and local expenditures however financed, $E$ is discretionary expenditures, and $E_{M}$ is expenditures mandated by the federal grant, defined above to equal $C / M_{C}$. Since the volume of mandated expenditures, determined by case $\mathrm{C}$ grants and their matching rates, are by definition exogenous, explaining $E$ is tantamount to explaining $E X P$.

The utility of state and local decision makers is then assumed to depend on the real value of mandated and discretionary expenditures, taken separately, adjusted for a measure of expenditure needs that is discussed below. Formally, utility depends on,

$$
Q_{1}=E / P_{E}+\gamma_{1} E_{M} / P_{E}-N,
$$

where $P_{E}$ is the expenditure price deflator to put the expression in real terms, $\gamma_{1}$ is the grant displacement parameter that allows for a differential utility from mandated as opposed to discretionary expenditures, and $N$ is a variable reflecting minimum expenditure needs.

If the grant displacement parameter, $\gamma_{1}$, is unity, mandated expenditures arising from case $\mathrm{C}$ grants and locally initiated discretionary expenditures lead to identical utility per dollar and can be considered perfect substitutes. In this event, categorical grants will turn out to have effects on total spending identical to those of lump-sum transfers. If $\gamma_{1}$ is less than 1 , on the other hand, mandated expenditures add less utility per dollar than do local discretionary expenditures; thus they must be only partially substitutable, the grant displacement is incomplete, and the effect of categorical $\mathrm{C}$ grants on total spending will be greater than that of lump-sum case B grants.

The term for expenditure needs, $N$, contains all demographic variables 
that change the marginal utility of expenditures, and hence spending propensities, without directly altering the budgetary situation of local governments. In principle many variables could meet these criteria; we tried a number of candidates but eventually settled on only three: (1) the number of school age children (KID), a proxy for education needs; (2) the number of families headed by females (FEM), a proxy for needs for welfare and other social services; (3) the robbery rate $(R O B)$, which is the best empirical proxy for needs for expenditures on public safety. We then let $N$ be a function of these three variables and substituted this expression into equation (2) in the maximization exercise. ${ }^{6}$

Private disposable incomes. The objective of higher private disposable incomes makes utility a positive function of pretax income $(Y)$ and a negative function of state and local taxes $(T)$. But allowance must be made for the possibility that equivalent changes in taxes and in pretax incomes will not necessarily lead to the same utility per dollar. If the state or locality could be thought of simply as an aggregation of households that cared only about total disposable income and not about whether its source was higher pretax incomes or lower taxes, the relevant indicator of satisfaction would be $(Y-T){ }^{7}$ But this may not be an accurate way to represent the state-local budgetary process if elected representatives imperfectly translate household preferences. In particular, if government officials have some independent influence on budgetary allocations, they would presumably prefer disposable income to rise through a cut in taxes, for which they can take credit, rather than through a rise in pretax earnings, for which they cannot. The community might then operate as if the utility associated with the disposable income objective were a function of

$$
Q_{2}=\gamma_{2} Y / P-T / P \text {, }
$$

where $\gamma_{2}$ sets the relative weight of private incomes and taxes in the preferences of decision makers, and the expression is put in real terms by deflating by the overall price level, $P$. If $\gamma_{2}$ equals 1 , decision makers are indifferent between income increases and tax reductions; if $\gamma_{2}$ is less than 1 , they prefer income to rise through a reduction in taxes. The relation be-

6. These "need" variables correspond loosely to the "supply" variables of James C. Ohls and Terence J. Wales, "Supply and Demand for State and Local Services," Review of Economics and Statistics, Vol. 54 (November 1972), pp. 424-30. The concept is also used in the work of McGuire, "Federal-Local Interactions," and Inman, "Four Essays."

7. For a more detailed discussion of the conditions under which this proposition holds, see Wallace E. Oates, Fiscal Federalism (Harcourt Brace, 1972), Chap. 3. 
tween the effect of private income increases and unrestricted lump-sum transfers on public spending will depend on this parameter $\gamma_{2}$. The two have identical effects when the source of the money is immaterial $\left(\gamma_{2}=1\right)$; and lump-sum transfers, which are already in the public treasury and therefore do not require the painful act of taxation, have a greater impact on spending if $\gamma_{2}$ is less than $1 .^{8}$

The stock of tangible capital. The third objective of state and local budgetary policy is to increase the flow of services from the stock of tangible capital. If this flow is proportional to the actual stock of capital, the utility from this source is also a proportional function of the stock.

To derive the utility expression, we begin with the identity, similar to that used for current expenditures, that total construction expenditures $(C O N)$ equals the sum of mandated $\left(I_{M}\right)$ and discretionary $(I)$ construction expenditures,

$$
C O N=I+I_{M}
$$

$I_{M}$ is again equal to $\left(C_{I} / M_{C I}\right)$, where $C_{I}$ and $M_{C I}$ equal case $\mathrm{C}$ construction grants and their matching ratio, respectively.

Two types of capital can then be distinguished, that resulting from the discretionary expenditures of local governments $(K O)$ and that resulting from mandated spending under current and previous categorical grants for construction $(K M)$. The earlier procedure can be used to define a parameter, $\gamma_{3}$, which measures the capital grant displacement effect in the same way that $\gamma_{1}$ measures the current grant displacement. With this parameter as a utility weight, the capital term in the utility function is proportional to

$$
Q_{3}=(1-\delta)\left(K O_{-1}+\gamma_{3} K M_{-1}\right)+I / P_{I}+\gamma_{3} I_{M} / P_{I},
$$

where $\delta$ is the rate of physical depreciation and $P_{I}$ the price index for new construction, and where the capital stock terms are both in real terms because they cumulate all past investments also measured in real terms. ${ }^{9}$

8. We might label this phenomenon the "flypaper" theory of incidence: Money sticks where it hits. Ray D. Whitman, in "Effect of Revenue Sharing Upon State-Local Fiscal Effort: A Revision of Current Theory" (paper prepared for delivery at the 1973 annual meeting of the Public Choice Society; processed), also gives other reasons why $\gamma_{2}$ might not equal 1. The argument in the text is proven formally in Appendix A.

9. Expressions for these two real stocks would be of the form,

$$
K O=\sum_{i=0}^{\infty}(1-\delta)^{i}\left(I / P_{I}\right)_{-i} ; \quad K M=\sum_{i=0}^{\infty}(1-\delta)^{i}\left[\left(1 / M_{C I}\right)\left(C_{I} / P_{I}\right)\right]_{-i} .
$$


This expression can be written in simpler notation as

$$
Q_{3}=K^{\prime}+I / P_{I}
$$

where

$$
K^{\prime}=(1-\delta)\left(K O_{-1}+\gamma_{3} K M_{-1}\right)+\gamma_{3} I_{M} / P_{I} .
$$

The stock of net financial assets. The fourth budgetary objective is to increase the flow of services from the stock of net financial assets. Net financial assets are defined here as all components of the net worth of states and localities other than real capital, or as all financial assets less all liabilities. This term in the utility function, $Q_{4}$, is simply given by the real stocks of financial assets:

$$
Q_{4}=\left(F A_{-1}\right) /(P)+(S / P),
$$

where $F A_{-1}$ represents stocks in the previous period and $S$ is current net financial saving.

\section{DERIVING THE ESTIMATING EQUATIONS}

In the real world a government obviously cannot satisfy all of these goals simultaneously-spend as much as it would like, tax as little as it would like, and maximize stocks of tangible capital and financial assets. Rather, it will have to allocate its limited resources among these competing objectives according to its perception of the highest priorities at that particular time. We describe this process through our optimization procedure.

Mathematically, we maximize the preference function,

$$
U=F\left(Q_{1}, Q_{2}, Q_{3}, Q_{4}\right),
$$

subject to a budget constraint. Since each of the terms in the utility function is assumed to have positive but declining marginal utility, governments will desire a smaller increment of any $Q_{i}$ the more they already have. Governments are assumed to use the four discretionary components of equation (8)-current expenditures $(E)$, construction expenditures $(I)$, taxes $(T)$, and financial saving $(S)$-to adjust to movements in the exogenous variables in (8)-expenditure needs $(N)$, expenditures mandated by case $\mathrm{C}$ grants $\left(E_{M}\right)$, income $(Y)$, and previous stocks of capital and financial assets $\left(K^{\prime}, F A_{-1}\right)$-in such a way as to establish this maximum continually. Solution of this system will lead to a set of estimating equations that describe how discretionary expenditures respond to these independent variables.

The budget constraint in this system is

$$
X=I+E+S-T,
$$


where $X$ (for exogenous budgetary resources) equals the algebraic sum of all nondiscretionary items-lump-sum transfers, interest and principal payments on outstanding debt, and the matching expenditures on categorical case $\mathrm{C}$ grants. The precise composition of this variable is demonstrated below and in Appendix A.

The optimization procedure, which is also worked out in detail in Appendix A, leads after a minor simplification to the following set of estimating equations for the four discretionary components:

$$
\left[\begin{array}{ll}
I / P_{I} \\
E / P_{E} \\
-T / P \\
\left.\left(F A_{-1}+X+T\right) / P-E / P_{E}-I / P_{I}\right]= & g\left\{\left(F A_{-1}+X\right) / P\right. \\
& (Y / P),\left(E_{M} / P_{E}\right), \\
& {\left[P_{E}\left(1-M_{A}\right) / P\right],} \\
& (R+\delta)\left(P_{I} / P\right), K^{\prime}, \\
& K I D, R O B, F E M\}
\end{array}\right.
$$

The fourth discretionary variable equals previous stocks of financial assets plus exogenous budgetary resources plus taxes less the two types of expenditures, with everything in real terms. This means that the sum of all four dependent variables is $\left(F A_{-1}+X\right) / P$, which is also the first independent variable. Such a system forces this variable to be allocated completely to expenditures, tax reductions, or surplus accumulation, with allocation coefficients that sum to unity across the four equations. These coefficients thus describe how either previous balances or exogenous budgetary resources will be split up among the four possible discretionary uses with all other independent variables held constant. All other independent variables will, on the other hand, have coefficients that sum to zero across the four equations. These coefficients will then change the allocation of any given level of exogenous budgetary resources in response to movements in the independent variables, without changing the overall total.

The lagged stock of financial assets in the budget constraint term gives the model somewhat complicated dynamic properties. If some outside change were, for example, to increase expenditures, either taxes would have to rise or the surplus would have to fall to preserve the budget identity. Whenever the surplus does change, stocks of financial assets will be lowered, leading governments to try to regain them either by increasing taxes or reducing expenditures. When they eventually do this, changes in the stock, or the current surplus, will cease. Financial assets are then acting as a buffer stock, with the surplus responding in the short run but not in the long run to changes in outside forces. 
The remaining independent variables and their expected roles in the budgetary allocation process are described as follows:

Real income $(Y / P)$. Real income will make communities better off and induce them to spend more on public goods and to increase stocks of capital and financial assets, by raising taxes (or reducing negative taxes).

Mandated expenditures under categorical case $C$ grants $\left(E_{M} / P_{E}\right)$. We use the exogenous amounts and matching ratios of closed-end categorical grants to determine the mandated level of spending under the grant program. States and localities are then free to vary their discretionary spending $(E)$ accordingly. If they reduce discretionary spending, they must also either increase their accumulation of financial assets or reduce taxes.

Relative prices. Relative prices alter discretionary spending and hence either taxes or the surplus. For current expenditures the appropriate price term is $P_{E}\left(1-M_{A}\right) / P$, or the relative price of expenditures times the implied price reduction due to case $\mathrm{A}$ grants. For construction there are no case A grants; but the relative price term, $(R+\delta)\left(P_{I} / P\right)$, where $R$ is the state and local interest rate and $\delta$ the rate of depreciation, allows the budgetary allocation to change in response to the opportunity cost of new investment.

Stocks of tangible capital. The capital stock objective implies that states and localities will invest more the less capital they have, and vice versa. Our theory reflects this by including the previous stock of capital, whether grant supported or not, as an independent variable, which lowers new construction and raises the other uses of budgetary resources. Apart from the residual financing effect, the lagged stock of structures should have a special stimulative effect on current expenditures for maintenance and for the wages of those who work in them.

Demographic terms. Each of these proxies for expenditure needs, KID, $R O B, F E M$, which were described earlier, should increase expenditures and also either increase taxes or reduce the surplus.

\section{Quarterly Time Series Estimates, Aggregate State and Local Sector}

\section{NATIONAL INCOME ACCOUNTS DATA}

The time series estimates of the model described above are based on data from the national income accounts for the aggregate state and local sector. These data cover the activities of two quite separate governmental 
Table 1. National Income Accounts Budget for State and Local General Governments and Social Insurance Funds, 1971

Billions of current dollars

\begin{tabular}{cc}
\hline Budget item & Amount \\
\hline Revenues, total & 151.8 \\
General government & 142.4 \\
Social insurance trust funds & 9.4 \\
Expenditures, total & 147.0 \\
General government & 145.1 \\
Social insurance trust funds & 1.9 \\
Benefit payments & $5.0^{\mathrm{a}}$ \\
Less: Interest earnings & -3.1 \\
Surplus, total & 4.8 \\
General government & -2.7 \\
Social insurance trust funds & 7.5 \\
\hline
\end{tabular}

Source: Survey of Current Business, Vol. 52 (July 1972), Tables 3.3, 3.7.

a. Includes a small amount of transfers to general government. Figures may not add to totals because of rounding.

bodies, general governments and the social insurance pension funds for state and local employees. The overall budget statement disaggregated into these two components is shown for 1971 in Table 1.

The table indicates that the trust funds accounted for more than the entire state and local surplus in 1971. Indeed, they have been chiefly responsible for growing surpluses in other recent years. Since trust funds are accumulating liabilities for retirement payments in the future, however, the implication of these high and rising surpluses is not clear. A positive trust fund surplus simply means that current inflows exceed benefit payments, but gives no indication whether these inflows are sufficient to meet future needs. Only a comparison of current receipts with those required to maintain the actuarial position of the funds-a measure that does not exist for state and local trust funds in the aggregate nor even for most individual fundscould resolve this question. ${ }^{10}$

What is clear, however, is that the transactions of retirement funds are motivated by quite different considerations from those influencing general governments. Since the model described here is meant to refer only to general governments, we have eliminated all trust fund items from the

10. See William B. Neenan, "Status of and Prospect for Municipal Retirement Plans" (Urban Institute, 1973; processed), for a more detailed description of the problems and prospects for trust funds. 
budget identity and will hereafter deal exclusively with general governments. The general government budget for 1971 is given in Table 2 .

Revenues consist of income, corporate, sales, and property taxes, along with a small amount of other revenues, plus federal grants. We have separated grants into types A (open-end), B (lump-sum), and C (closed-end categorical), with type $\mathrm{C}$ grants divided into those for current expenditures and those for construction. Total expenditures consist of construction and current outlays-each distributed between mandated and discretionary expenditures-and interest payments minus the surplus of government enterprises.

Table 3 then displays the budget divided into its discretionary and nondiscretionary components. Because we have simply transferred various items from one side of the ledger to the other, the budget identity still holds; now, however, it implies that the sum of the four discretionary items - two types of discretionary expenditures plus the budget surplus minus taxes-equals total nondiscretionary budgetary resources, $X$.

Table 2. National Income Accounts Budget for State and Local General Governments, by Major Revenue and Expenditure Items, 1971

Billions of current dollars

\begin{tabular}{cr}
\hline Revenue or expenditure item & Amount \\
\hline Revenues, total & 142.4 \\
Taxes and other & 113.1 \\
Federal grants-in-aid & 29.3 \\
Open-end (A) & 10.8 \\
Lump-sum (B) & 0.1 \\
Closed-end categorical (C) & 18.4 \\
Construction & 8.4 \\
Current expenditures & 10.0 \\
Expenditures, total & 145.1 \\
Construction & 26.2 \\
Mandated by federal C grants & 10.5 \\
Discretionary & 15.7 \\
Other purchases and transfer payments & 120.5 \\
Mandated by federal C grants & 11.5 \\
Discretionary & 109.0 \\
Interest payments & 2.8 \\
Less: Surplus of government enterprises & -4.3 \\
Surplus, total & -2.7 \\
Retirement of long-term debt (gross) & 7.8 \\
Cash flow surplus & -10.5 \\
\hline
\end{tabular}

Sources: Table 1 above; Survey of Current Business (July 1972), Table 3.3; U.S. Bureau of Economic Analysis, unpublished data. Figures may not add to totals because of rounding.

a. Net of a small trust fund transfer to general government. 
Table 3. National Income Accounts Budget for Discretionary and Nondiscretionary Components of State and Local General Governments, 1971

Billions of current dollars

\begin{tabular}{lc}
\hline \multicolumn{1}{c}{ Component } & Amount \\
\hline Nondiscretionary budgetary variable $(X)$ & -5.4 \\
Federal open-end A grants $\left(M_{A} \bar{E}\right)$ & $8.7 \mathrm{a}$ \\
Federal lump-sum B grants $(B)$ & 0.1 \\
Less: Drain due to federal closed-end categorical C grants, & \\
$\quad$ construction $\left(I_{M}-C_{I}\right)$ & -2.1 \\
Less: Drain due to federal C grants, current expenditures $\left(E_{M}-C\right)$ & -1.5 \\
Less: Interest and debt retirement $(D)$ & -10.6 \\
Discretionary budgetary variables & -5.4 \\
Construction expenditures $(I)$ & 15.7 \\
Current expenditures $(E)$ & 109.0 \\
Cash flow surplus $(S)^{\mathrm{a}}$ & -12.7 \\
Less: Taxes and surplus of government enterprises $(T)$ & -117.4 \\
\hline
\end{tabular}

Source: See Table 2.

a. An estimate of the income effect of $\mathbf{A}$ grants, the matching rate $M_{A}$ times a previous average of values for expenditures, $\bar{E}$, is included on the nondiscretionary side of the budget. See text for discussion. Since this income effect is different from actual A grants (Table 2), the budget surplus also has been changed.

Three items in the table deserve special mention. Since the level of categorical $\mathrm{C}$ grants is exogenous, the expenditures from own sources necessary to match these grants, $\left(E_{M}-C\right)$ and $\left(I_{M}-C_{I}\right)$, appear on the nondiscretionary side. These local expenditures are a drain on budgetary resources and thus become a negative component of the budgetary resource variable.

A second matter requiring explanation is our treatment of case A grants. These grants are included in the exogenous term in Table 3 to account for the income effect of the implied expenditure price reduction. Like any other price change, A grants operate through a substitution effect which shifts prices with budgetary resources constant, and an income effect which changes budgetary resources with prices constant. Even when states and localities do not respond to the price reduction implied by case A grants, they are still getting revenue from such grants based on previously planned expenditures which they are likely to use as they do other nondiscretionary funds. To capture this income effect, we have included an A grant term in $X$, defining it as the current matching rate, $M_{A}$, times a previous average of values for expenditures, $\bar{E}{ }^{11}$

11. This adjustment is a way of simplifying an equation system that becomes nonlinear when all prices are not the same. There is also a much smaller income effect working through the interest and debt retirement term, $D$, for the opportunity cost of investment expenditures. See Appendix A for details. 
Finally, we have classified interest payments and the retirement of longterm debt as exogenous - the first because they are determined by current and previous market interest rates and the predetermined stock of debt, and the second because they too depend on the predetermined stock of debt, as well as on its repayment schedule. This dependence in itself would not make debt retirement expenditures exogenous if states and localities were able to prepay or refinance their debt so as to alter its payment schedule. But most of these governmental units are legally prevented from refinancing their long-term debt, and few have been known to prepay it. Thus for these purposes we have lumped debt retirement with interest payments as a negative component of $X$.

\section{The Estimates}

We estimated the model given in equation (8) with seventy-six quarterly time series observations from 1954 through 1972. All variables reflecting dollar flows were in real terms and all prices were entered as ratios, as suggested by the maximization exercise. We deflated all the dollar variables and demographic terms by population to correct for any common trends that might be introduced by sheer growth. ${ }^{12}$ Since the response of the state and local sector to outside influences is likely to be sluggish even apart from the lag working through the surplus described above, we have also used distributed lags (denoted by $L$ ) for these independent variables, which are difficult to predict and for which we might expect a lag. ${ }^{13}$

12. Another rationalization for this technique might be that expenditure decisions are probably made in terms of real services delivered per capita. We tried to take this reasoning one step further by assuming that tax decisions were made in terms of effective rates on income, and to distinguish between discretionary taxes involving changes in these rates and nondiscretionary taxes involving changes in income. This approach yielded results similar to those presented here but somewhat less reliable statistically, possibly because discretionary and nondiscretionary taxes are difficult to distinguish operationally.

13. The three demographic terms in the quarterly model were all interpolations of annual numbers. Since each of these series was already smoothed, it did not seem worthwhile to use distributed lags for them.

In addition, it is especially important to compute a lag distribution for the expenditures implied by categorical grants. These expenditures are subtracted from total expenditures to compute the discretionary component (see equation 1) at the same time that they are addedas an independent variable in equation (10). This procedure builds a negative bias into the estimates if there is measurement error due to the timing of federal categorical grants. We have attempted to adjust for this kind of error by smoothing our 
Estimation of the equations proceeded in two stages. First, each of the four equations for the discretionary variables of equation (10) was estimated separately by ordinary least squares. These initial estimates were used to eliminate independent variables that did not work well in the equation for the dependent variable they should primarily affect, and to measure the shape of the lag distributions, the degree of serial correlation of residuals, and the size of the remaining standard errors. The estimated degree of serial correlation was high enough to justify using all observations in firstdifference form. Final coefficient estimates were then obtained from a second regression in which these first differences were stacked in such a way as to impose the budget constraint and ensure that each of the four equations had the same weight in influencing the structure of the coefficients. ${ }^{14}$

The best estimates of this set of equations are given in Table 4. Some of the cells in the table are blank because the relevant coefficient was either insignificant or had an incorrect sign and was dropped from the specification. But the only independent variable that did not have the expected sign in any of the four equations was the relative price for current expenditures. This means that A grants have no price substitution effects in this version.

The coefficients in the table give the impact effect in the first quarter of changes in the independent variables. Because resources not spent or used for tax reduction add to the current surplus, they continue to influence budgetary allocations in future quarters. Ultimate long-run effects are discussed in the next section.

We retained the lagged resources term, $L_{1} / X$, despite its relatively low $t$-ratio because this was the only avenue through which construction responded to changes in budgetary resources. (The current value of $X$ has almost no effect on construction.) But even with relaxed standards of significance, we found no influence of lagged resources on current expenditures and taxes.

series for all case $\mathrm{C}$ grants before subtracting them from total expenditures, and then using a distributed lag on this smoothed series as the independent variable for categorical grants.

14. The stacking technique is described in Frank de Leeuw, "A Model of Financial Behavior," in James S. Duesenberry and others (eds.), The Brookings Quarterly Econometric Model of the United States (Rand McNally, 1965). The stacked equations were then weighted by the inverse of the standard error of the ordinary least squares estimation after correction for serial correlation to ensure that equations with large residuals would not unduly influence the overall coefficients. 


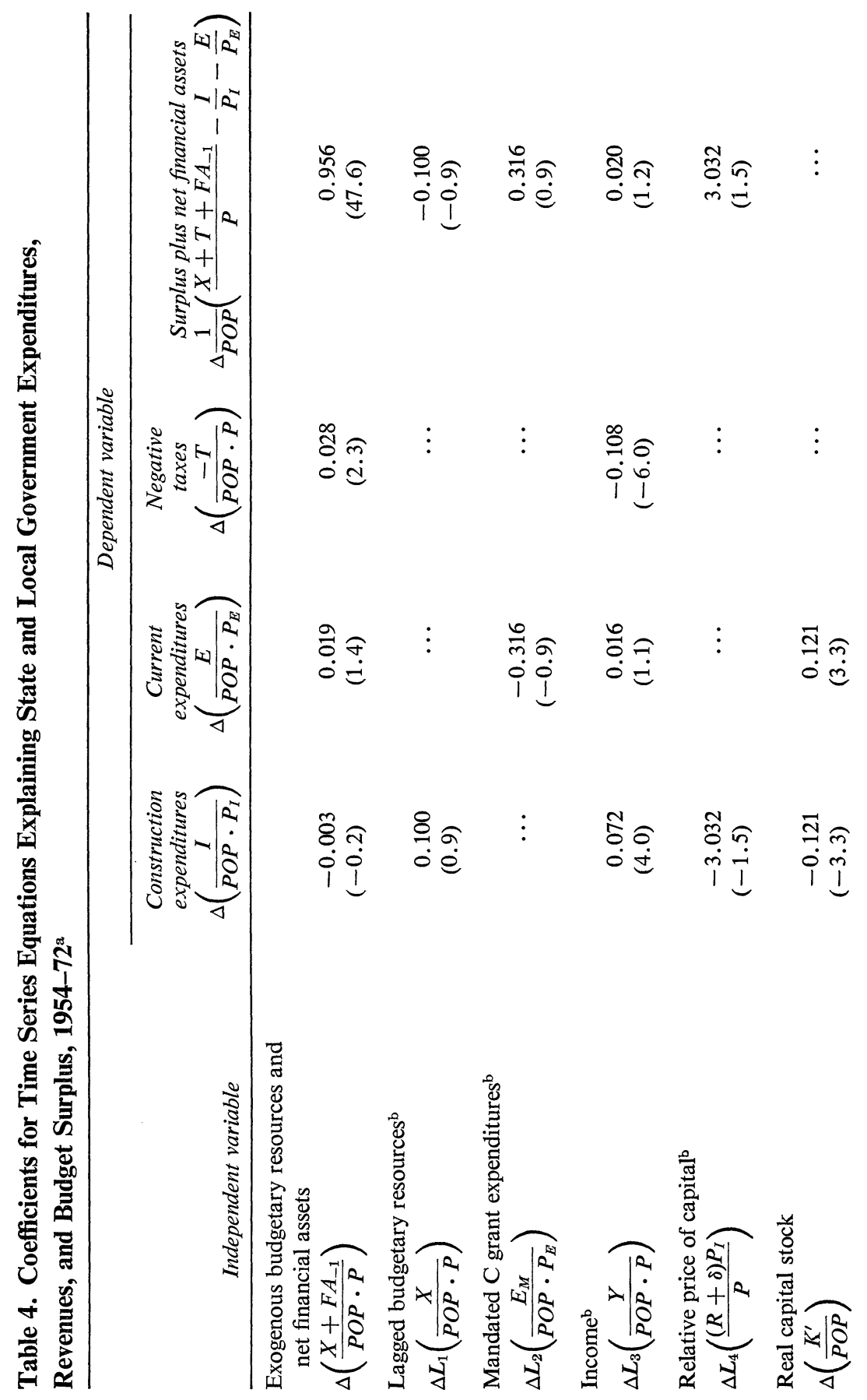




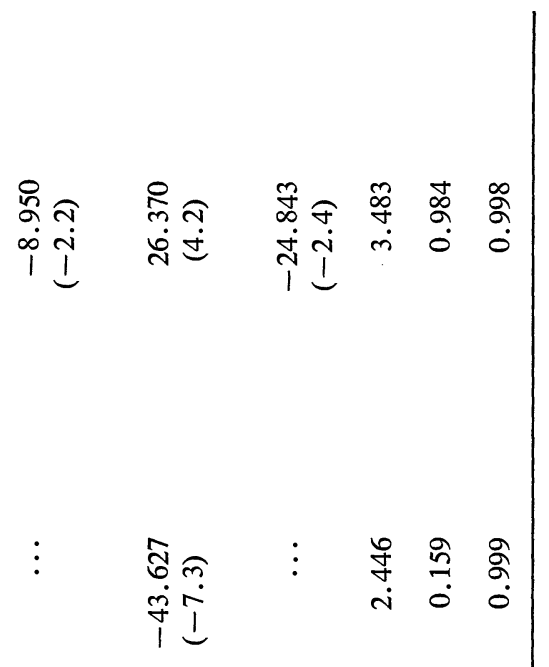

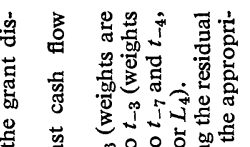

荡

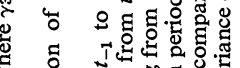

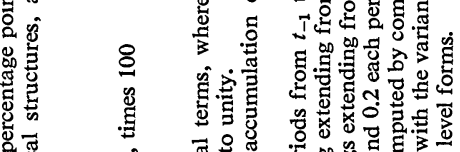

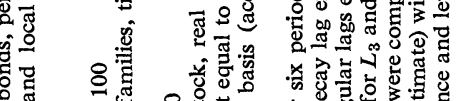

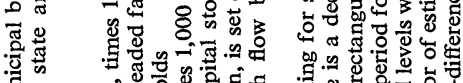

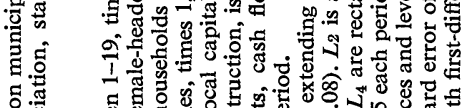

品 苋造

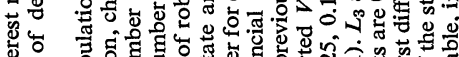

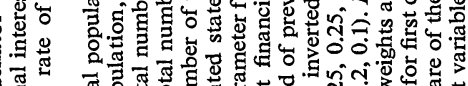

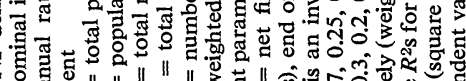

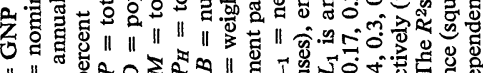

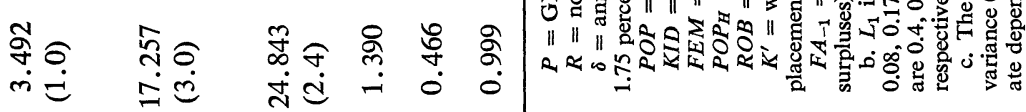

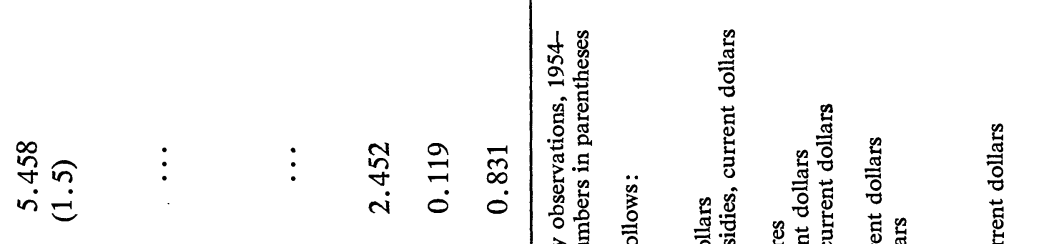


The coefficients for $\left(X+F A_{-1}\right)$ indicate a very sluggish response of both current expenditures and taxes to changes in previous balances or exogenous inflows of funds. A rise of $\$ 1$ in some inflow-say, lump-sum transfers-will increase the surplus by $\$ 0.96$ in the first quarter, with only a slight increase in expenditures and a small reduction in taxes. After one year the surplus will be higher by $\$ 0.75$, with $\$ 0.25$ going into expenditure increases and tax reductions; after two years the proportions are about fifty-fifty. Of the two, expenditures approach their equilibrium value very slightly faster than do taxes.

The coefficients for mandated $\mathrm{C}$ grant expenditures indicate that the reaction of expenditures would be much faster in this instance. A rise in $\mathrm{C}$ grants will immediately increase total expenditures by $E_{M}$, as given in equation (1). Then discretionary expenditures will decline by an amount that equals $\$ 0.32$ per dollar of change in $E_{M}$ over a period of four quarters. This decline in discretionary spending will also be reflected as a rise in the surplus, which ultimately again raises discretionary expenditures by a small amount. If matching rates are set equal to one, a $\$ 1$ rise in $\mathrm{C}$ grants will stimulate $\$ 0.88$ total expenditures in the first quarter, about $\$ 0.70$ in the fourth quarter when the displacement effect has had time to work, and about $\$ 0.75$ in the eighth quarter, by which time the increase in the surplus has begun to feed back on expenditures.

\section{EQUILIBRIUM CHANGES}

Solving these equations for their equilibrium properties once all lags have been played out provides a better idea of their long-run properties. This is done by determining the equilibrium stocks of capital and financial assets and substituting them into the relationships for current expenditures and the negative of taxes. The current surplus is unchanged in this equilibrium, and investment is changed only by altered replacement needs. In these calculations we have added mandated $\mathrm{C}$ grant expenditures to discretionary expenditures to produce results in terms of total state and local expenditures, a more familiar concept. The steady-state magnitudes are given in Table 5.

Several results stand out in the table. A dollar of revenue sharing or of any other exogenous budgetary inflow will ultimately raise expenditures by $\$ 0.43$ and lower taxes by $\$ 0.57$. The current expenditure response to revenue sharing is roughly five times that of the response to private income, 


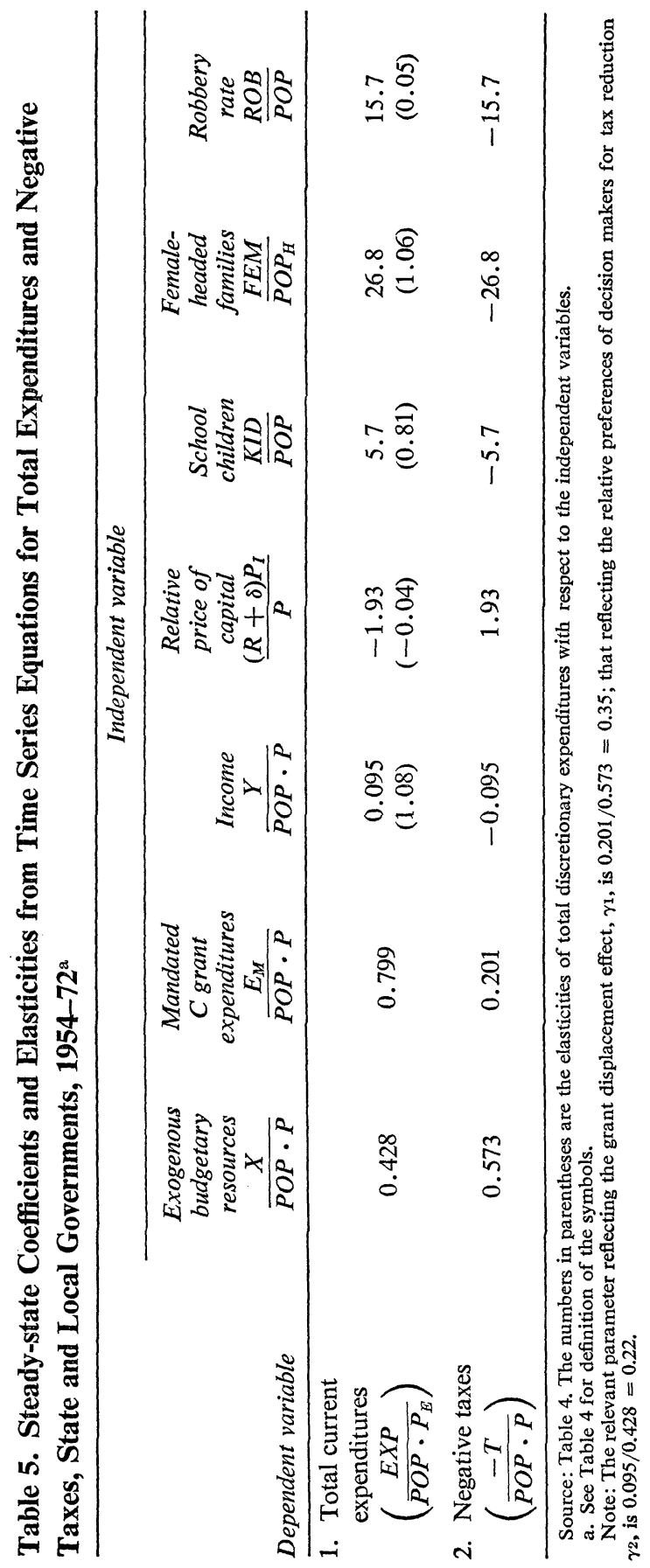


an extra dollar of which eventually produces only $\$ 0.10$ of current expenditures in equilibrium. This implies a relative utility weight, $\gamma_{2}$, of 0.22 for income-that is, that income received in the public treasury $(X)$ has a much different effect from income received by private households $(Y)$.

The displacement of categorical matching grants is relatively slight in this version $\left(\gamma_{1}=0.35\right)$, indicating that categorical case $\mathrm{C}$ grants with a matching ratio of unity will increase total spending by $\$ 0.80$, almost twice as much as does revenue sharing. ${ }^{15}$ The expenditure impact is even greater when matching rates are below unity, or when the federal government pays less than the full cost of the expenditure program, because under these circumstances the initial level of mandated spending is higher, with this impact only partly offset by the negative income effect of the budgetary drain due to matching. By way of illustration, if matching rates were equal to their present average federal share of 80 percent $\left(M_{C}=0.8\right)$, total expenditures would increase by $\$ 1.00-(\$ 0.80)(1 / 0.8)$-through the mandated $\mathrm{C}$ grant term in Table 5, to be offset by $\$ 0.10-(0.43)(\$ 1.25-\$ 1.00)$ - through the exogenous budgetary resource drain in Table 5, for a net increase of $\$ 0.90$. This evidence of a fairly strong impact from categorical $\mathrm{C}$ grants appears to conflict with the estimated weak effects on spending of case A grants. However, as mentioned above, such a result could be explained by effective effort maintenance requirements for case $\mathrm{C}$ grants, resulting either from legal restrictions or from the fact that case $\mathrm{C}$ grants have been used more extensively for new expenditure programs.

The other variables operate in relatively predictable ways. In order to facilitate their interpretation, we have also presented these results in terms of elasticities, or ratios between the marginal coefficients and average ratios, for the relevant concept of discretionary expenditures. The income elasticity of discretionary expenditures is 1.08 , implying that state and local discretionary expenditures grow slightly faster than income. The interest rate elasticity of expenditures is very slightly negative because the capital stock, whose operation and maintenance are responsible for some of these expenditures, is negatively related to interest rates. The elasticity of expen-

15. Computation of these values for $\gamma_{1}$ and $\gamma_{2}$ is described in Appendix A and also in the note to Table 5. The effect of displacement $\left(\gamma_{1}=0.35\right)$ is calculated as follows: The impact of $\$ 0.80$ is 35 percent of the way between the impact if there were no displacement $\left(\$ 1.00\right.$ when $\left.M_{C}=1.0\right)$ and the revenue-sharing impact if displacement were complete $(\$ 0.43)$. 
ditures with respect to the number of school children is 0.81 . This may appear high in view of the fact that only about half of total expenditures are for schools; but some other expenditures for social services, welfare, and public safety also depend partially on numbers of children. The elasticity with respect to the robbery rate is very small, as would be expected from the fact that it should raise expenditures on only a small portion of the expenditure budget. The one variable with a coefficient that seems high is that reflecting families headed by females. Though its effects should also be restricted to certain types of expenditures, it nevertheless has an elasticity of 1.06, suggesting that it may be serving as a proxy for some other influences.

Although these results give some indication of the impacts of different types of grants, a fair amount of uncertainty remains. It is surprising that the impact per dollar of case $\mathrm{C}$ grants appears to be greater than that of revenue sharing while the impact of open-end A grants does not. For revenue sharing itself, the results - that somewhat less than half the funds actually will augment expenditures-are reasonably plausible, but the inference arises from a variable that has not included revenue sharing until now and for which the $t$-ratio is rather low. The next section then compares these inferences with those of the same model estimated with another body of data.

\section{Pooled Cross-section Estimates, Ten Large Urban Governments}

The equations presented in this section come from a budgetary model based on data for ten large urban governments. These data have the advantages, first, of permitting identification of aggregation effects, and, second, of including revenue-sharing money from state governments along with their other components of budgetary inflows. With these pooled crosssection data, there is also enough information to disaggregate expenditures into functional categories and thus to estimate separate price substitution effects and the displacement propensities of categorical grants for the different categories.

One of the problems in using local government data is that jurisdictions overlap. Typically, residents in any one area will be served by a city or town government, a county government, and probably, for certain func- 
tions, special districts. This makes it very difficult to examine the behavior of any one government in isolation, because it depends crucially on what all the other local governments serving the same geographic area are doing or have done in the past. We have tried to get around this problem by choosing for our sample only jurisdictions that were served by one general government during the estimation period. A relatively homogeneous sample of ten large urban city-county governments met this criterion: Baltimore, Boston, Denver, New Orleans, New York, Philadelphia, Providence, St. Louis, San Francisco, and Washington, D.C. We then defined for these cities a standard discretionary public sector, consisting of education, public safety, social services (health and hospitals, housing), urban support (sewage, sanitation, highways, parks and recreation), and general government, but excluding airports, water transport, mass transit, higher education, and some other items. All expenditures and revenues of general government and special districts within our standard public sector were part of the general government, and only net drains due to these excluded items were deducted from exogenous budgetary inflows $(X)$. Another negative component of $X$ was the cost (net of federal case A grants) of city expenditures on welfare, which are basically set by state laws determining caseloads and payment levels and are therefore exogenous to cities.

A further problem concerns the fact that these large urban governments are typically surrounded by high-income areas that might limit their fiscal flexibility. Cities may feel unable to tax and spend as much as they like because these suburbs offer a potential tax haven to wealthy city residents. ${ }^{16}$ We have allowed for this possibility by including real per capita taxes on suburban property in the model, expecting increases in this variable to make city governments more willing to increase their own taxes and expenditures.

Table 6 gives the pooled cross-section equations, using annual first differences stacked as before to impose the budget constraint and to ensure that all equations had the same weight in estimating the coefficients. We have disaggregated discretionary current expenditures into five components, each with its own price (two of which are not significant) and federal and state categorical grant programs (two of which are not present because there are no grant programs in these areas). In addition, no separate data

16. For the original statement that consumers choose among tax and expenditure packages of competing jurisdictions, see Charles M. Tiebout, "A Pure Theory of Local Expenditures,” Journal of Political Economy, Vol. 64 (October 1956), pp. 416-24. 
on investment are available and thus the entire current account surplus, or change in net worth $(\Delta N W)$, is included as the last dependent variable, where $\Delta N W$ is again defined by subtracting all other discretionary uses of resources from $X .{ }^{17}$

Our attempts to include the level of net worth as one independent variable, and hence ensure that this stock would be unchanged in the long run, were not successful. Although such an equation can be estimated with fairly sensible long-run coefficients, the estimated time period over which this adjustment appears to take place is unreasonably long. Thus for the cross-section results we adopted an alternative specification that merely used the previous change in net worth as one independent variable, and hence did not fully distribute all changes in private income and budgetary resources to current expenditures and taxes. All other independent variables have a direct impact on expenditures and taxes, however, and their long-run effects can be determined apart from the behavior of the surplus.

In contrast to the time series results of Table 4, the equations in Table 6 show significant price substitution terms. Categorical federal grants now have statistically significant displacement effects for education, but not for the other two categories. (The coefficient is large and negative for urban support, but federal grants in this area are very small and the estimate is unreliable.) The suburban tax and robbery variables worked well, but not the school-age population variable, possibly because it is difficult to measure between Census years for individual cities. The variable incorporating the number of families headed by females was not even included because it should mainly affect welfare, which is not endogenous in the cross-section model. Other demographic variables reflecting expenditure needs-such as the proportion of aged people in the population, population density, the poverty population, the nonwhite population - typically did not yield very significant effects.

\section{EQUILIBRIUM CHANGES}

The steady-state coefficients for these equations are given in Table 7 . For exogenous budgetary resources and income, which had effects on the

17. Since our pooled cross-section equations are estimated to only nine time series observations for any one city, using lags on the independent variables imposes a real cost in terms of loss of information. Thus we have not computed direct lags for any variable except grants (see note 13). 


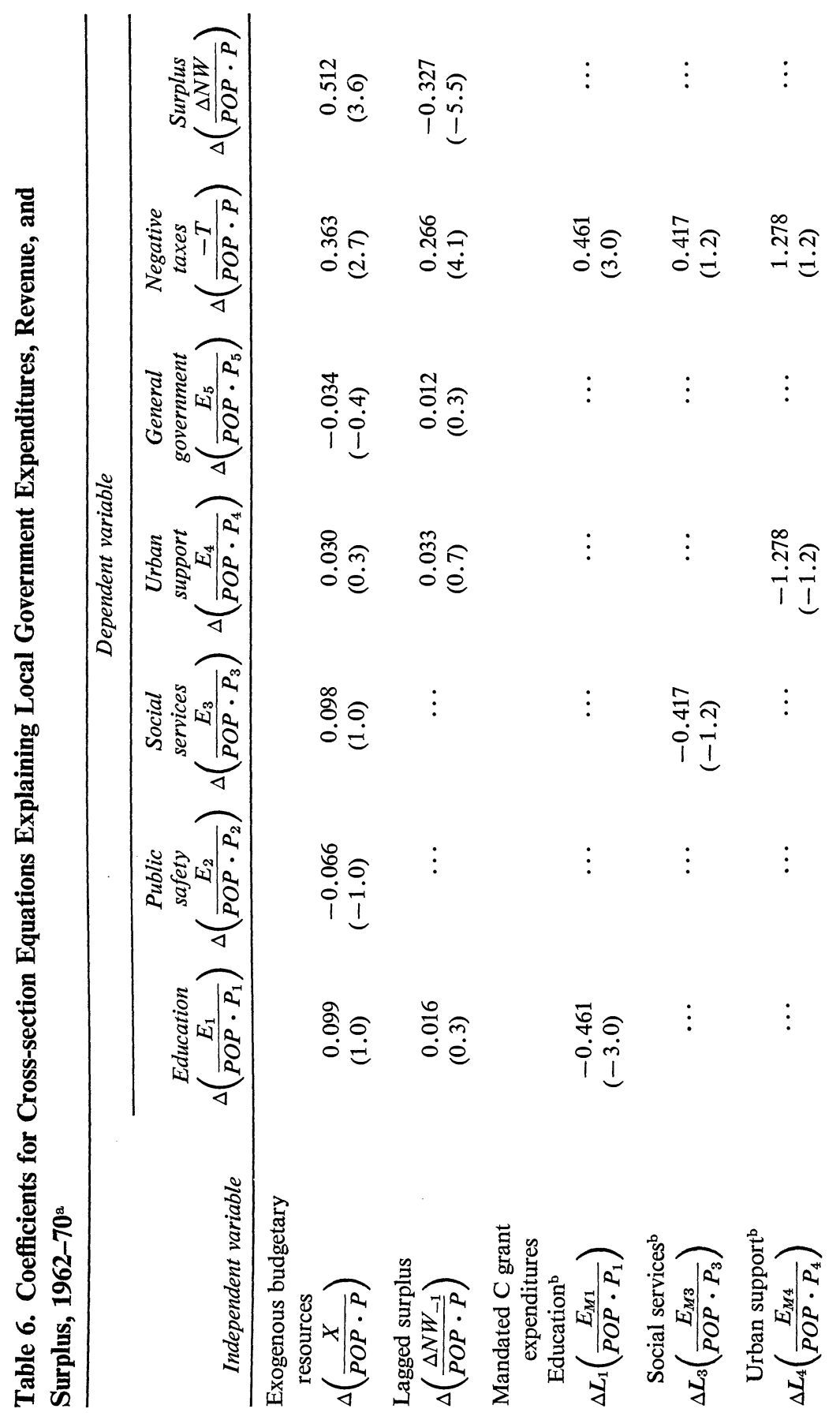




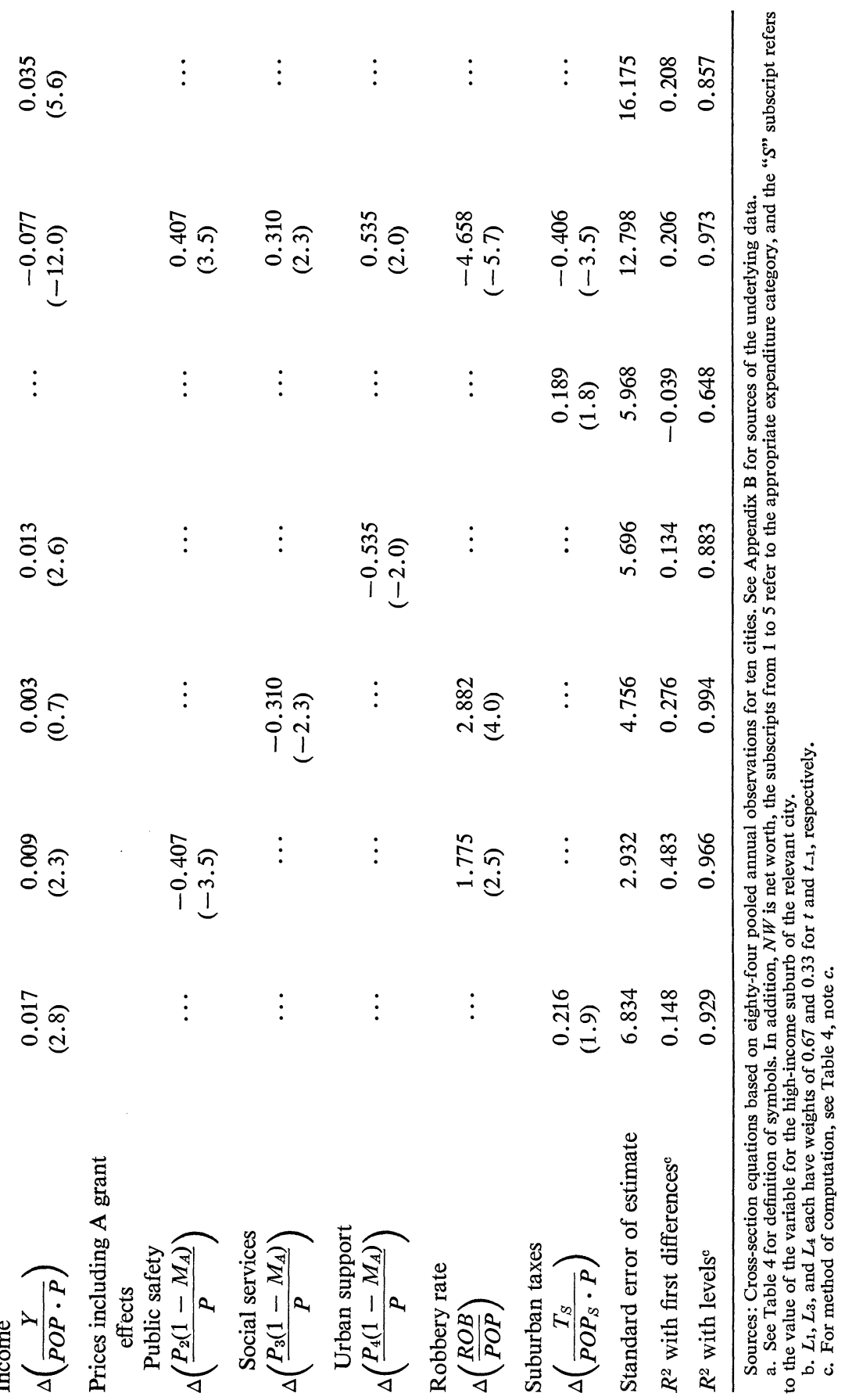


surplus, we used the pattern of coefficients in the lagged surplus to determine the steady-state effects. Because the other independent variables did not affect the current surplus, their steady-state coefficients are the same as the impact coefficients in Table 6 . Again, nondiscretionary expenditures are added in to present the table in terms of total expenditures, and the five functional components are also summed.

The effect of a dollar of revenue sharing on expenditures is weaker than in the time series estimates, with only $\$ 0.25$ going to expenditures and $\$ 0.75$ to tax reduction. This effect is still roughly five times the effect of income on expenditures, meaning that $\gamma_{2}$, the utility weight for income, remains about the same as before. The effect of categorical grants on spending is lower than before, however, because the displacement parameters, $\gamma_{11}, \gamma_{13}$, and $\gamma_{14}$, are larger than in the time series estimates. Each dollar of $\mathrm{C}$ grants now stimulates between $\$ 0.54$ and $\$ 0.58$ of additional spending for education and social services and actually reduces spending for the small urban support category. The pattern of these estimates suggests that grant displacement is greater the smaller are federal grants relative to local discretionary expenditures, or the more likely cities are to spend this amount of money on programs even in the absence of grants. These equations also indicate that the three significant price elasticities are in the -0.7 to -0.9 range, which implies that A grants stimulate spending by about $\$ 0.80$ per dollar (see Appendix A for calculations), or by more than $\mathrm{C}$ grants. The one exception to this result is education, where the price substitution effect is absent but where categorical grants do stimulate more spending than lump-sum transfers and A grants. Such a finding is again inconsistent with the theory of grants unless there is a high degree of effective effort maintenance with case $\mathrm{C}$ grants for education.

\section{The Impact of Federal Grant Policy on State and Local Expenditures}

The results of this paper suggest that lump-sum transfers such as general revenue sharing will, for the first year, show up mainly as an increase in the accumulation of financial assets by states and localities. As stocks of assets rise, governments will be less inclined to expand them further, however, and will gradually use this new wealth to increase expenditures and reduce taxes. Ultimately, after about five years, each dollar of revenue sharing will enlarge state and local spending by about $\$ 0.43$ according to 


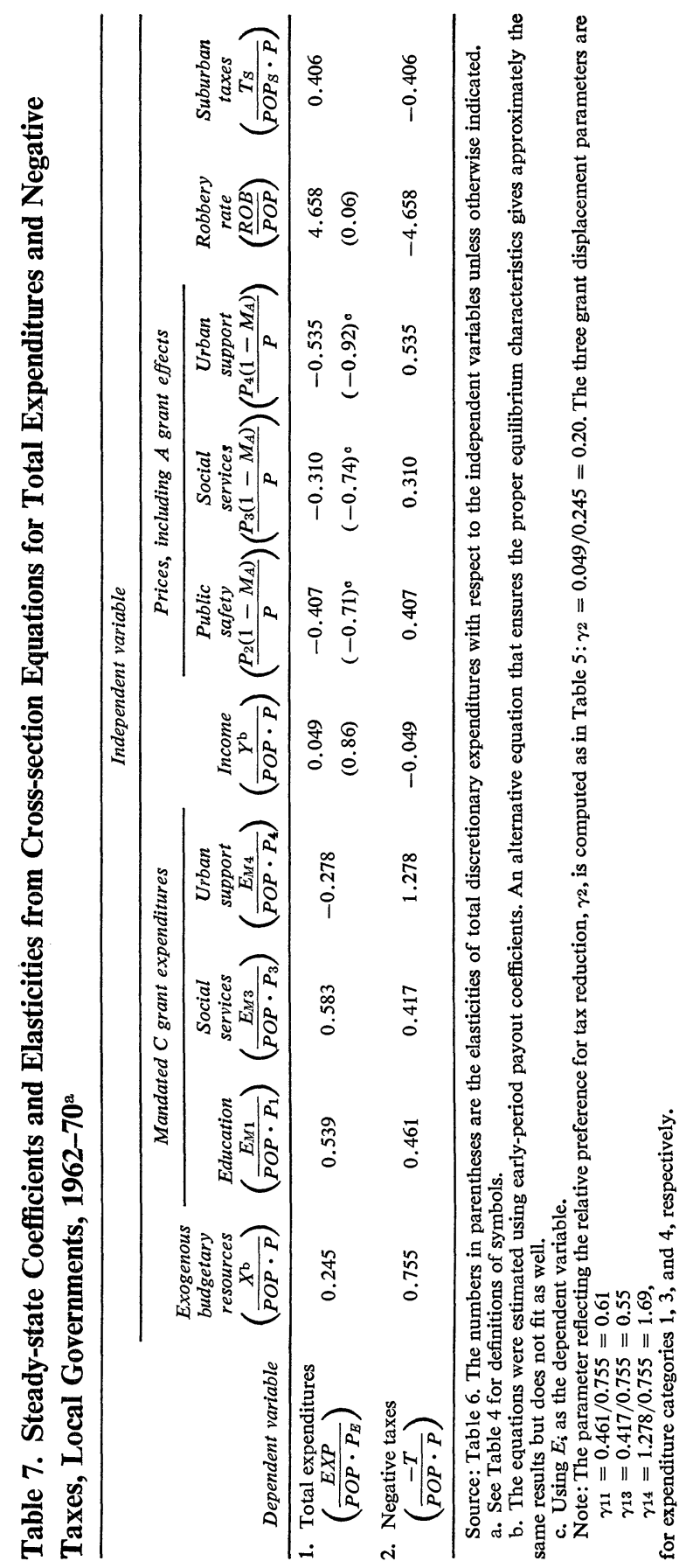


the time series estimates and by about $\$ 0.25$ according to the cross-section equations. ${ }^{18}$ Although neither set of coefficients is estimated with much precision, together they indicate that a sizable part of revenue-sharing grants will result in reduction of state and local taxes below what they otherwise would have been. It also appears that revenue sharing will have less impact on expenditures than categorical grants but more impact than private incomes.

The estimated effects of categorical grants also differ between the time series and cross-section equations. In the time series versions, there is little evidence that categorical grants displace discretionary expenditures, with the result that grants increase total state and local spending by about $\$ 0.90$ per dollar at present matching rates. Even this estimate is smaller than those reported by most other studies. ${ }^{19}$ More displacement is estimated in the cross-section equations; there, categorical grants for education and social services increase expenditures by about $\$ 0.65$ per dollar at present matching rates, and grants for urban support do not seem to increase expenditures even as much as do lump-sum transfers. In each case the displacement occurs quickly, so that expenditures and taxes are nearly at their equilibrium values by the end of the first year.

The time series equations revealed no price substitution effects for case A grants, which means that their effects are no larger than those of lumpsum transfers and are even smaller than those of categorical $\mathrm{C}$ grants. The cross-section equations did uncover significant, and fairly sizable, price substitution effects in three of the five categories of expenditure. In these categories A grants would stimulate spending by about $\$ 0.80$ per dollar, or by slightly more than would categorical $\mathrm{C}$ grants.

Even if these numbers were perfectly reliable, they still would be difficult to use in appraising current policy actions regarding grants. General revenue sharing, for example, comes as close to being a pure lump-sum transfer as one would want. Yet even here, some restrictions are imposed on the

18. We know of only two other studies that report coefficients for the effect of lump-sum transfers on total expenditures. John C. Weicher, "Aid, Expenditures, and Local Government Structure," National Tax Journal, Vol. 25 (December 1972), pp. 573-83, finds this parameter to be higher; McGuire, "Federal-Local Interactions," finds it to be lower.

19. The most recent paper on this topic is Thomas O'Brien, "Grants-in-Aid: Some Further Answers," National Tax Journal, Vol. 24 (March 1971), pp. 65-77. A long list of previous studies was summarized in Edward M. Gramlich, "The Effect of Federal Grants on State-Local Expenditures: A Review of the Econometric Literature," National Tax Association, Proceedings of the Sixty-second Annual Conference on Taxation, 1969 (1970), pp. 569-93. 
uses to which local governments can put the money, and expenditures are subject to a minor additional stimulus due to a provision that distributes money partly on the basis of tax effort. ${ }^{20}$ Furthermore, somewhat more money per capita goes to poorer governments, which may have higher spending propensities. And, finally, local governments may feel that the distribution could be temporary and that they must spend the money on programs to demonstrate their continuing need. Although the precise influence of these forces is impossible to determine, the estimated range for the equilibrium expenditure impact of $\$ 0.25$ to $\$ 0.43$ per dollar of grantapproximately $\$ 1.3$ billion to $\$ 2.3$ billion for a general revenue-sharing distribution of $\$ 5.5$ billion-is probably somewhat low. All things considered, general revenue sharing ultimately should stimulate approximately $\$ 2$ billion to $\$ 3$ billion of additional expenditures at the state-local level, after fairly long lags.

The administration proposals to convert categorical grants to special revenue sharing are even more difficult to analyze. The proposed legislation combines many existing narrow categorical grant programs into broad special revenue-sharing grants for education, community development, manpower, and law enforcement. All matching requirements and effort maintenance restrictions are eliminated, as are many of the other restrictions on the uses to which the grant money can be put. In analyzing these proposals, account must then be taken both of the nature of the displacement operating in the particular grant being folded into special revenue sharing and of the types of restrictions included in the legislation.

In the limiting case in which the special revenue-sharing categories are defined so broadly that states and localities have broad scope for internal displacement, and in which other restrictions are minimal, special revenue sharing will operate much like a lump-sum transfer. In this event, converting an average categorical grant to special revenue sharing will reduce state and local spending by about $\$ 0.40$ per dollar in either the time series or the cross-section estimates, or roughly $\$ 2.8$ billion in terms of the administration's proposal to convert $\$ 6.9$ billion of grants. ${ }^{21}$ In the other limiting case, in which all present restrictions are continued and the matching rate

20. See Charles J. Goetz, "Federal Block Grants and the Reactivity Problem," Southern Economic Journal, Vol. 34 (July 1967), pp. 160-65; and Richard A. Musgrave and A. Mitchell Polinsky, "Revenue-Sharing, A Critical View," Financing State and Local Governments, Proceedings of the Monetary Conference Sponsored by the Federal Reserve Bank of Boston, June 1970 (FRBB, 1970), pp. 17-52.

21. Special Analyses, Budget of the United States Government, Fiscal Year 1974, Special Analysis N. 
$\left(M_{C}\right)$ is simply set at unity, the average reduction in state and local spending would be about $\$ 0.10$ per dollar in either set of equations, or only $\$ 0.7$ billion. The real impact should fall somewhere between these extremes, depending on the provisions of special revenue sharing, but will probably fall closer to the higher figure.

Apart from these effects on overall expenditures, the interesting social questions concerning categorical grants and whether they should be converted into special revenue sharing require examination of the programmatic distribution of funds within these overall totals. This paper provides some evidence that such distributional questions are important, for the displacement effects of present categorical grants suggest that states and localities may now to some extent frustrate the implied purpose of the federal grant programs, and may do so to an even greater extent if present restrictions on the use of the money are relaxed. But to determine the implications of such shifts requires a much more detailed and disaggregated study of the operation of individual grant programs.

\section{The Meaning of Recent Movements in the State-Local Budget Surplus}

For the postwar period as a whole, state and local general governments have greatly enlarged their stocks of tangible capital, partially by increasing stocks of net financial obligations. Thus even though the net worth of general governments has risen, their national accounts budget has typically been in deficit by about $\$ 3$ billion annually. This deficit has been almost exactly offset by the retirement fund surplus, which has averaged about the same amount, although these deficits and surpluses have not been identical at all times.

In 1971 and 1972, however, this picture changed radically. The overall state and local surplus reached a postwar high of $\$ 3.8$ billion in the second quarter of 1970 and then, after slipping back briefly, rose to the remarkable amount of $\$ 19.5$ billion in the fourth quarter of 1972 . This sharp increase has raised some eyebrows, including those of David Ott and his associates, who have wondered whether the federal government was "impoverishing itself while putting the states and local governments as a group in a position of relative fiscal affluence." ${ }^{22}$ In this section we use our model to examine the implications of this growth in the surplus.

22. Ott and others, Nixon, McGovern, and the Federal Budget, p. 3. This phenomenon hac alen heen noticed hv the Offire of Management and Rudoet though as mioht he 
Our dynamic theory suggests that changes in the surplus take the brunt of the immediate adjustment of state and local budgets to outside forces. For example, most of any exogenous inflow of funds initially swells the surplus, and only gradually affects expenditures or taxes. Similarly, in the first round, changes in other independent variables, such as income, prices, nondiscretionary expenditures, or the demographic terms, affect the activity to which they are directly related and the surplus; later, they affect other, competing, activities, which are affected by this change in the surplus. Viewed in this light, the surplus is really the mechanism through which the lagged response of the entire state and local budget to an outside change takes effect-or the temporary cushion that allows state and local governments flexibility in planning.

In the long run, by contrast, the surplus is assumed not to respond at all to outside forces. Once states and localities have used exogenous inflows of funds to build up their stocks of net financial assets through short-run surpluses, they have no further need to accumulate or decumulate.

These observations underlie an examination of the experience of the 1970-72 period reported in Table 8. The first row in the table gives the gross surplus on the national income accounts basis of the state and local sector, the series that has caused all the excitement. The second row then gives our quarterly estimate of the surplus of state and local retirement funds, which rose to $\$ 8.6$ billion in 1972 . Earlier we argued that it was difficult, if not impossible, to read this number as an indication of the financial strength of retirement funds, since information about the present value of their contractual obligations is not available; it follows therefore that it indicates little about the financial position of state and local general governments.

The third row gives the general government surplus after retirement fund surpluses have been deducted. Before these numbers can be interpreted, two accounting adjustments must be made for special factors that artificially altered the pattern of the surplus in 1972. The first adjustment undoes the effect of an advance payment of public assistance grants in the second quarter of 1972 , which raised the surplus $\$ 4.0$ billion at annual rates in the second quarter and will reduce it correspondingly in the first quarter of 1973. The second adjustment is for general revenue sharing, which was passed by Congress after the third quarter was over, with a

expected, not as a prelude to questioning revenue sharing. See Budget . . 1974, Special Analysis N. 


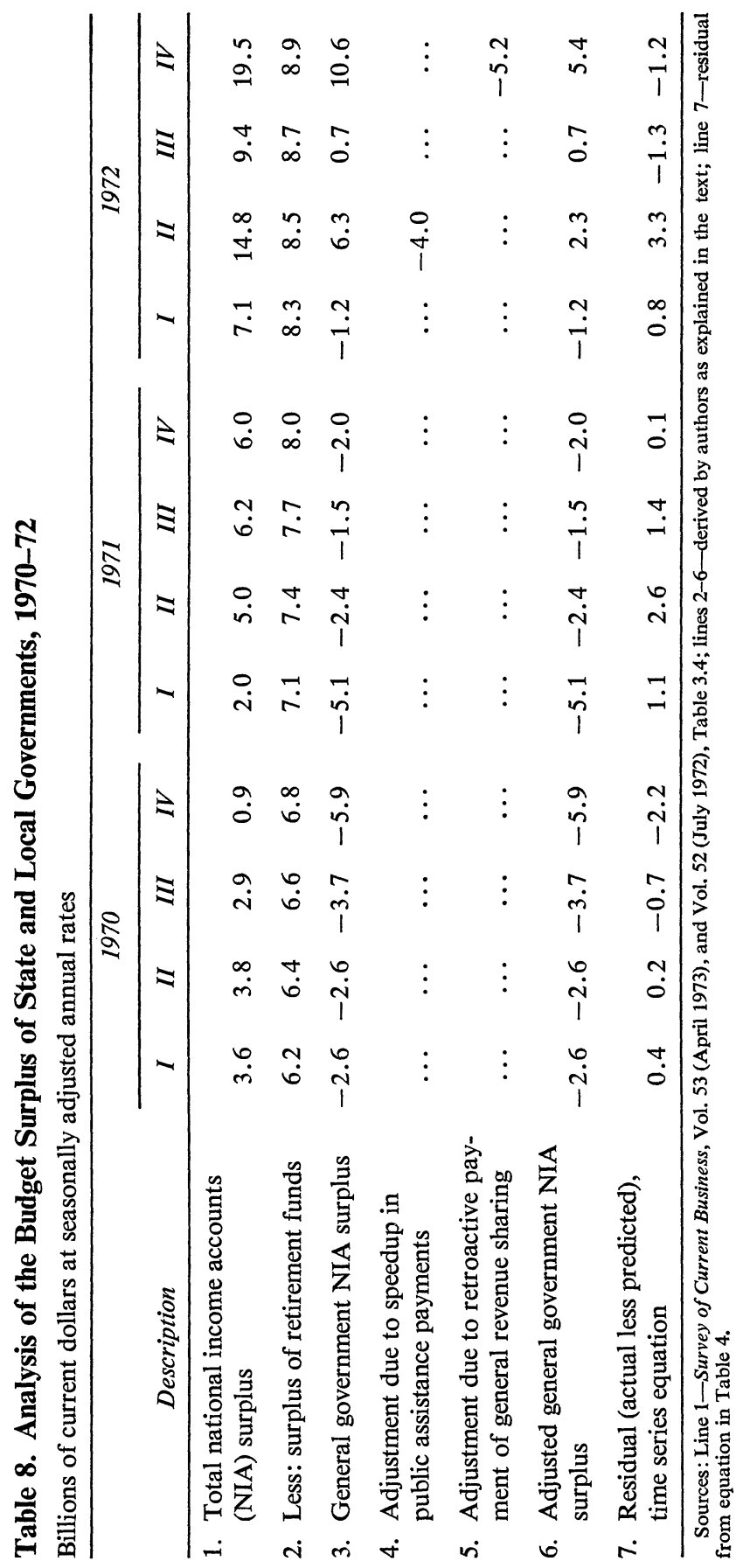


double payment of $\$ 10.5$ billion ( $\$ 5.2$ billion retroactive, $\$ 5.3$ billion current) made in the fourth quarter. Table 8 retains the current payment but line 5 and hence line 6 eliminate the fourth quarter retroactive payment from the surplus.

The resulting adjusted general government surplus (line 6) looks much less remarkable than the published series (line 1). There was still a rise, totaling \$11.3 billion between the low point in the fourth quarter of 1970 and the high point in the fourth quarter of 1972, but this rise could have been expected over the period. Our equations indicate that in the first quarter of general revenue sharing, more than 95 percent of the $\$ 5.3$ billion disbursement could be expected to be saved, thus immediately accounting for $\$ 4.8$ billion of this change in the surplus. In addition over the two-year interval the growth in real income was responsible for another $\$ 1.5$ billion, and the growth in other grants and the demographic factors (mainly the decline in numbers of school children) for another $\$ 4.0$ billion; the residual increased only $\$ 1.0$ billion. In fact, after account has been taken of all of the independent variables in our equation, the 1972 residuals (line 7) do not reveal anything very surprising: They are not very large and are even negative in the last two quarters.

Moreover, even if all of the independent variables remain at their recent levels - and at least the grant and demographic variables should do sothis discussion suggests that the high general government surpluses should be reduced and eventually eliminated. Precisely because state and local governments have used this period to build up their stocks of net financial assets, they are likely to use their new-found financial cushion to allocate their surpluses into higher flows of expenditures or reductions in taxes, with somewhat more going to the latter according to our estimates. ${ }^{23}$ Whether one believes this process to be an unwarranted "impoverishment" of the federal government then depends not on the size of the surplus, which should decline, but on whether one prefers his tax reductions and expenditure increases to occur at the state and local or national level.

\section{Conclusion}

The aim of this paper has been to assess the role of federal grants and other factors in influencing the budgetary behavior of state and local gov-

23. Notice that this statement applies only to general governments. There is no reason why the trust fund surplus, and therefore the overall state and local surplus, 
ernments. It has distinguished among three different types of grants-those that operate only through prices, those that operate only through budgetary inflows, and those that have both price and income effects. It has estimated equations that allow for different responses for the different types of grants, along with income and other demographic factors, all the time ensuring that the estimates are internally consistent from a budgetary standpoint.

Although the results are tenuous and should be accepted with a good deal of caution, we find that pure lump-sum transfers are likely to stimulate between $\$ 0.25$ and $\$ 0.43$ of expenditures for each dollar of grant. This range must be adjusted upwards before it is applied to the recently enacted general revenue sharing due to several minor additional stimuli to expenditures in the legislation; thus we would expect $\$ 5.5$ billion of revenue sharing to increase state-local spending by $\$ 2$ billion to $\$ 3$ billion. The administration's proposal to convert $\$ 7$ billion of categorical assistance to special revenue sharing is, on the other hand, likely to reduce overall state and local spending by $\$ 1$ billion to $\$ 3$ billion, according to our estimates.

Further, we do not read much into the recent sharp growth in the state and local budget surplus on the national income accounts basis. Over half the surplus in 1972 was earned by state and local retirement funds; but the surplus is not a good indicator of their present financial health. The remaining portion resulted directly from the initiation of general revenue sharing, cyclical movements in income, and the decline in numbers of school-age children. But even if these forces were to continue, we feel confident that the surpluses would ultimately be reduced in favor of a combination of higher state-local expenditures and lower taxes. If a case is to be made against revenue sharing, it is not that the present state and local budget surplus is too high, but that the prospective mix of additional expenditures and tax reductions has a lower priority than some other federal use of this money.

should stop growing. Ott and his associates also seem to be somewhat ambivalent on their outlook for the overall surplus (Nixon, McGovern, and the Federal Budget, p. 24). 


\section{APPENDIX A}

\section{Derivation of Estimating Equations}

\section{The Preference Function}

Assume we have a utility function made up of quadratic terms in the four objectives mentioned in the text (using the same notation):

$$
\begin{aligned}
U & =\sum_{i=1}^{4}\left(a_{i 1} Q_{i}-\frac{a_{i 2}}{2} Q_{i}^{2}\right), \\
Q_{1} & =\frac{E}{P_{E}}+\frac{\gamma_{1} E_{M}}{P_{E}}-N \\
Q_{2} & =\frac{\gamma_{2} Y}{P}-\frac{T}{P} \\
Q_{3} & =K^{\prime}+\frac{I}{P_{I}} \\
Q_{4} & =\frac{F A_{-1}}{P}+\frac{S}{P}
\end{aligned}
$$

where each $a_{i j}$ and $Q_{i}$ is positive.

The expression is maximized subject to the budget identity

$$
\begin{aligned}
\text { (A-2) } I(1+R+\delta)+E\left(1-M_{A}\right)+S-T \\
=B+C_{I}-I_{M}+C-E_{M}-D^{\prime}=X^{\prime},
\end{aligned}
$$

where $D^{\prime}$ gives the interest and debt retirement payments on previously incurred debt and $I(R+\delta)$ gives them on current debt. Solving this system by differentiating with respect to each discretionary variable and setting these derivatives equal to zero yields 
(A-3)

$$
\begin{aligned}
& {\left[\begin{array}{l}
a_{32}+a_{42}\left(P_{I} / P\right)^{2}(1+R+\delta)^{2} \\
a_{42}\left(P_{I} / P\right)(1+R+\delta)\left[P_{E}\left(1-M_{A}\right) / P\right] \\
a_{42}\left(P_{I} / P\right)(1+R+\delta) \\
a_{42}\left(P_{I} / P\right)(1+R+\delta)\left[P_{E}\left(1-M_{A}\right) / P\right] \\
a_{12}+a_{42}\left[P_{E}\left(1-M_{A}\right) / P\right]^{2} \\
a_{42}\left[P_{E}\left(1-M_{A}\right) / P\right] \\
a_{42}\left(P_{I} / P\right)(1+R+\delta) \\
a_{42}\left[P_{E}\left(1-M_{A}\right) / P\right] \\
a_{22}+a_{42}
\end{array}\right]\left[\begin{array}{c}
I / P_{I} \\
E / P_{E} \\
-T / P
\end{array}\right]=\left[\begin{array}{c}
Z_{1}^{\prime} \\
Z_{2}^{\prime} \\
Z_{3}^{\prime}
\end{array}\right],}
\end{aligned}
$$

with

$$
\begin{gathered}
\begin{aligned}
& Z_{1}^{\prime}=a_{31}-a_{32} K^{\prime}- a_{41}\left(P_{I} / P\right)(1+R+\delta) \\
&+a_{42}\left(P_{I} / P\right)(1+R+\delta)\left[\left(F A_{-1} / P\right)+\left(X^{\prime} / P\right)\right] \\
&\left.Z_{2}^{\prime}=a_{11}-a_{12} \gamma_{1} E_{M} / P_{E}+a_{12} N-a_{41}\left[P_{E}\left(1-M_{A}\right) / P\right)\right] \\
&+a_{42}\left[P_{E}\left(1-M_{A}\right) / P\right]\left[\left(F A_{-1} / P\right)+\left(X^{\prime} / P\right)\right] \\
& Z_{3}^{\prime}=a_{21}-a_{22} \gamma_{2} Y / P-a_{41}+a_{42}\left[\left(F A_{-1} / P\right)+\left(X^{\prime} / P\right)\right]
\end{aligned}
\end{gathered}
$$

This set of equations has numerous multiplicative terms in the price ratios and must be linearized to simplify the estimation. ${ }^{1}$ If we approximated the expression by merely dropping the multiplicative price terms, however, we would be ignoring the income effects of relative prices, interest rates, and case A grants and forcing these variables to work only through

1. Other commonly used utility functions, such as that implicit in the Stone-Geary "linear expenditure system," also required similar transformations to derive linear estimating equations. The original references on the linear expenditure system are Richard Stone, "Linear Expenditure Systems and Demand Analysis: An Application to the Pattern of British Demand," Economic Journal, Vol. 64 (September 1954), pp. 511-27; and R. C. Geary, "A Note on 'A Constant-Utility Index of the Cost of Living," Review of Economic Studies, Vol. 18 (1950-51), pp. 65-66. That this system is in fact nonlinear in its parameters can be seen from Richard W. Parks, "Maximum Likelihood Estimation of the Linear Expenditure System," Journal of the American Statistical Association, Vol. 66 (December 1971), pp. 900-03. 
their substitution effects. Whenever these substitution effects did not appear, which was in fact the case in our time series equations for current expenditures and for some of the cross-section expenditure categories, changes in relative prices and A grants would show no effect at all on state and local budgets.

We have avoided this difficulty by including the income effect component of all relative price terms in the budget resources variable. Since this variable ensures that all relative price terms have income effects, the presence or absence of substitution effects will then determine whether A grants are more powerful than other grants. The new budgetary resources variable is written as

$$
X=X^{\prime}+M_{A} \bar{E}-(R+\delta) I=I+E-T+S ;
$$

the A grant term is an instrumental variable approximating the inflow of funds from this source and the opportunity cost on new investment is included in the variable defined as $D$ in Table 3 . Then the nonlinear price terms in (A-3) can be dropped, and the equation rewritten:

$$
\begin{aligned}
& {\left[\begin{array}{c}
I / P_{I} \\
E / P_{E} \\
-T / P \\
F A / P
\end{array}\right]=} \\
& \frac{1}{A_{0}}\left[\begin{array}{cc}
\left(a_{12} a_{22}+a_{12} a_{42}+a_{22} a_{42}\right) & -a_{22} a_{42} \\
-a_{22} a_{42} & \left(a_{22} a_{32}+a_{22} a_{42}+a_{32} a_{42}\right) \\
-a_{12} a_{42} & -a_{32} a_{42} \\
-a_{12} a_{22} & -a_{22} a_{32}
\end{array}\right. \\
& \left.\begin{array}{cc}
-a_{12} a_{42} & a_{12} a_{22} a_{42} \\
-a_{32} a_{42} & a_{22} a_{32} a_{42} \\
\left(a_{12} a_{32}+a_{12} a_{42}+a_{32} a_{42}\right) & a_{12} a_{32} a_{42} \\
-a_{12} a_{32} & a_{12} a_{22} a_{32}
\end{array}\right]\left[\begin{array}{l}
Z_{1} \\
Z_{2} \\
Z_{3} \\
\left(F A_{-1}+X\right) / P
\end{array}\right],
\end{aligned}
$$


where

$$
\begin{aligned}
A_{0} & =a_{12} a_{22} a_{32}+a_{12} a_{22} a_{42}+a_{12} a_{32} a_{42}+a_{22} a_{32} a_{42} \\
Z_{1} & =a_{31}-a_{32} K^{\prime}-a_{41}\left(P_{I} / P\right)(1+R+\delta) \\
Z_{2} & =a_{11}-a_{12} \gamma_{1} E_{M} / P_{E}+a_{12} N-a_{41}\left[P_{E}\left(1-M_{A}\right) / P\right] \\
Z_{3} & =a_{21}-a_{22} \gamma_{2} Y / P-a_{41} \\
F A / P & =F A_{-1} / P+X / P-I / P_{I}-E / P_{E}+T / P .
\end{aligned}
$$

Notice that this expression has a fourth dependent variable, equal to the deflated stock of financial assets, to ensure that the four discretionary variables sum to $\left(F A_{-1}+X\right) / P$, its four coefficients to unity, and the coefficients of each $Z$ to zero. This expression is the one actually estimated, after substitution for each $Z{ }^{2}$

\section{Equilibrium Solution}

We can investigate the equilibrium properties of these equations by assuming that both construction expenditures and the surplus will be zero and $E / P_{E}-T / P=X / P$. Equation (A-5) becomes

$$
\begin{aligned}
& {\left[\begin{array}{c}
E / P_{E} \\
-T / P
\end{array}\right]=} \\
& \frac{1}{B_{0}}\left[\begin{array}{ccc}
b_{32} b_{42} & -b_{32} b_{42} & b_{22} b_{32} b_{42} \\
-b_{32} b_{42} & b_{32} b_{42} & b_{12} b_{32} b_{42}
\end{array}\right] \\
& {\left[\begin{array}{l}
b_{11}-b_{12} \gamma_{1} E_{M} / P_{E}+b_{12} N-b_{41}\left[P_{E}\left(1-M_{A}\right) / P\right] \\
b_{21}-b_{22} \gamma_{2} Y / P-b_{41} \\
X / P
\end{array}\right],}
\end{aligned}
$$

where

$$
B_{0}=b_{12} b_{32} b_{42}+b_{22} b_{32} b_{42} \text {. }
$$

2. Strict substitution of $Z_{1}$ into (A-3) will lead to the conclusion that $K^{\prime}$ will have the same coefficients as $F A_{-1}$ in the equations for $E,-T$, and $F A$; and therefore that $K^{\prime}$ should be added to $I$ just as $F A_{-1}$ was added to $S$. We did not make this transformation in our estimation because some current expenditures are necessary to keep capital in operation and thus allow the entire capital stock to enter the utility function. This difficulty can be handled by including $K^{\prime}$ as an additional argument in $N$, which means that its true coefficient from $Z_{1}$ and $Z_{2}$ is not $a_{32}$, and hence $K^{\prime}$ must be entered as a separate variable in the regressions. 
Here we have replaced all short-run $a_{i j}$ coefficients with their equilibrium $b_{i j}$ counterparts. In the text we do this operation numerically by solving the equations for construction and net financial assets for their equilibrium stocks, inserting these stocks in the equations for expenditures and taxes, and solving again for the equilibrium coefficients of the remaining variables.

\section{Effects of Different Types of Grants}

These long-run equations determine the effects of different types of grants on expenditures. Using only the relevant coefficients, we have

$$
\begin{aligned}
E X P / P_{E} & =E / P_{E}+E_{M} / P_{E}=\left(1 / B_{0}\right)\left[\left(b_{12} b_{32} b_{42}+b_{22} b_{32} b_{42}\right) E_{M} / P_{E}\right. \\
& -\gamma_{1} b_{12} b_{32} b_{42} E_{M} / P_{E}+b_{32} b_{42} b_{41} M_{A} P_{E} / P \\
& \left.+b_{22} b_{32} b_{42}\left(M_{A}(E / P)+B / P+C / P-E_{M} / P\right)\right] .
\end{aligned}
$$

The effect per dollar of A grants is then

$$
\begin{aligned}
\Delta\left(E X P / P_{E}\right) / \Delta & \left(M_{A} E / P_{E}\right) \\
& =\left(1 / B_{0}\right)\left[b_{22} b_{32} b_{42}\left(P_{E} / P\right)+b_{32} b_{42} b_{41}\left(P_{E} / E\right)\left(P_{E} / P\right)\right] .
\end{aligned}
$$

This expression equals $\alpha /\left(1-M_{A}\right)$, where $\alpha$ is the negative of the elasticity of real discretionary expenditures with respect to relative prices. This illustrates the statement in the text that $\mathrm{A}$ grants increase expenditures more the higher is the elasticity of demand.

The per dollar effect of $\mathbf{B}$ grants is unambiguously smaller, or

$$
\Delta\left(E X P / P_{E}\right) / \Delta\left(B / P_{E}\right)=\left(1 / B_{0}\right)\left[b_{22} b_{32} b_{42}\left(P_{E} / P\right)\right]
$$

And the effect per dollar of $\mathrm{C}$ grants $\left(E_{M}=C / M_{C}\right)$ is

$$
\begin{aligned}
& \Delta\left(E X P / P_{E}\right) / \Delta\left(C / P_{E}\right)=\left(1 / B_{0}\right)\left[b_{12} b_{32} b_{42}\left(1-\gamma_{1}\right)\left(1 / M_{C}\right)\right. \\
& \left.+\left(b_{22} b_{32} b_{42}\right)\left(1 / M_{C}\right)\left(P-P_{E}\right) / P+b_{22} b_{32} b_{42}\left(P_{E} / P\right)\right] .
\end{aligned}
$$

If $\gamma_{1}=1$, that is, if the expenditures mandated under $\mathrm{C}$ grants completely displace discretionary expenditures, and if $P_{E}=P, \mathrm{C}$ grants have effects identical to $\mathrm{B}$ grants regardless of the matching rate. If $\gamma_{1}<1$, $\mathrm{C}$ grants have effects larger than $\mathrm{B}$ grants, but, although this exercise 
cannot show it, still smaller effects than A grants as long as there are no effort maintenance restrictions.

Finally (A-6) indicates that the parameters describing grant displacement $\left(\gamma_{1}\right)$ and the relative utility weight of income and taxes $\left(\gamma_{2}\right)$ can be computed from these long-run coefficients:

$$
\begin{gathered}
\gamma_{1}=\frac{\Delta(T / P) / \Delta\left(E_{M} / P_{E}\right)}{\Delta(T / P) / \Delta(X / P)} \\
\gamma_{2}=\frac{\Delta\left(E / P_{E}\right) / \Delta(Y / P)}{\Delta\left(E / P_{E}\right) / \Delta(X / P)} .
\end{gathered}
$$

\section{APPENDIX B}

\section{Data Sources}

ThIS APPENDIX LISTS the definitions of the variables used in the study and their sources.

\section{Time Series Estimates}

Federal grants by type and matching ratio: Calculated by determining the characteristics of each grant program from Catalog of Federal Domestic Assistance, Compiled for the Executive Office of the President by the Office of Economic Opportunity (April 1970 and October 1971).

Long-term state and local debt retired: U.S. Bureau of the Census, Governmental Finances, various years (adjusted and interpolated quarterly).

Total population and population aged 1-19: Economic Report of the President, Together with the Annual Report of the Council of Economic Advisers, January 1973, Table C-23 (interpolated quarterly).

Families headed by females: Bureau of the Census, Current Population Reports, Series P-20, "Household and Family Characteristics," various years (interpolated quarterly).

Number of robberies: U.S. Federal Bureau of Investigation, Uniform Crime Reports for the United States, various years (interpolated quarterly). 
Municipal bond interest rate: Moody's Investors Service, Aaa bond rate, as published in Federal Reserve Bulletin, various issues.

The following variables have been taken from various issues of the Survey of Current Business or from worksheets of the U.S. Bureau of Economic Analysis (BEA), generously made available to us by Charles Waite:

State and local financial data, including expenditures, receipts, and surplus (Survey, Table 3.4).

State and local pension funds data, including expenditures, receipts, and surplus (Survey, Table 3.7, interpolated quarterly).

Price deflator for GNP (Survey, Table 8.1).

Price deflators for state and local compensation, construction, and other purchases (BEA worksheets).

Real GNP (Survey, Table 1.2).

Federal grants to state and local governments, by program (BEA worksheets).

\section{Pooled Cross-section Estimates}

Financial data for cities and suburbs: U.S. Bureau of the Census, unpublished worksheets adjusted by the Urban Institute.

Federal and state grants by type and matching ratio: Calculated by determining the characteristics of each government program from U.S. Bureau of the Census, Census of Governments, 1967, Vol. 6, Pt. 4, State Payments to Local Governments (1968), and Catalog of Federal Domestic Assistance, Compiled for the Executive Office of the President by the Office of Economic Opportunity (April 1970).

Population data: U.S. Bureau of the Census, U.S. Census of Population, 1960, Final Report PC (1), General Social and Economic Characteristics (individual state reports) (1961), and U.S. Census of Population, 1970, Final Report PC (1), General Social and Economic Characteristics (individual state reports) (1972) (interpolated geometrically between 1960 and 1970).

Number of robberies: U.S. Federal Bureau of Investigation, Uniform Crime Reports for the United States, various years.

Personal income: U.S. Bureau of Economic Analysis, "Personal Income by Major Sources and Earnings by Broad Industrial Sector," special computer tabulations prepared for the Urban Institute. 
Consumer price index: U.S. Bureau of Labor Statistics, The Consumer Price Index, various issues.

Wages for teachers: National Education Association, Salary Schedule and Fringe Benefits for Teachers (formerly Salary Schedules for Teachers), various years; calculated by averaging minimum and maximum annual wages for teachers with a B.A. degree.

Wages for firemen and policemen: International City Management Association, The Municipal Year Book (Washington: ICMA, various years); calculated by averaging minimum and maximum annual wages for firemen and policemen.

Wages in social services and basic urban support functions: American Hospital Association, American Hospital Association Guide to the Health Care Field (Chicago: AHA, various years); Bureau of Labor Statistics, Wages and Related Benefits, various years (the title of the publication varied over the period covered); annual earnings calculated by dividing annual payroll for hospital employees by the number of employees.

Wages in housing, sewerage, sanitation, water supply, highways, parking facilities, parks and recreation, and urban renewal: Set equal to average hourly earnings for laborers in nonmanufacturing.

Wages in social services and overhead (general control and judicial, general public buildings, financial administration, protective inspection and regulation, general government, and miscellaneous commercial activities): Set equal to average weekly earnings for office clerical workers in nonmanufacturing. 


\section{Comments and Discussion}

Stephen Goldfeld: I enjoyed reading this paper, and wish to commend the authors for their efforts to estimate the effects of various grant policies on state and local government spending.

I would like to outline several noteworthy features of this exercise. First, it is significant that the estimating equations are derived from an explicit model that ensures that everything that comes in must go out somewhere. This consistent additivity feature, which is often absent in this kind of study, is an important aspect both in the short and in the long run. The second feature-also a step in the right direction-is the attempt to distinguish between $\mathrm{A}, \mathrm{B}$, and $\mathrm{C}$ grants, and to allow for different income and price effects. Finally, it is noteworthy that the authors attempt to use both time series and cross-sectional data to answer their empirical questions.

The main empirical conclusions that are drawn from the data are generally plausible. However, the time series results unfortunately appear to be sensitive to the estimating procedures. As might be expected, a rather wide confidence band appears to surround the 0.43 estimate of the stimulative impact of lump-sum transfers, although no confidence band for that coefficient is ever actually calculated due to the complicated procedures that would be involved. In any case, the authors should not be faulted, as these estimates-especially the time series results-are presented very circumspectly.

Let me touch on several of the problems that I think are involved in this type of analysis. First, it is difficult to obtain much from a time series 
analysis of B grants, since they did not really exist over the sample period. Moreover, the $X$ variable, which is designed to capture the same kind of influence as the B grant, is composed of very small numbers. Thus very little confidence can be attached to these particular estimates.

Another problem is the variety of categorical (C) grants. For example, some types of $\mathrm{C}$ grants support currently existing programs while others fund brand new programs or incremental expenditure. If the mix of these types of grants changes over the sample period, then one would not expect to capture the effect of $\mathrm{C}$ grants with the single variable that is used in the paper. Basically, that variable would not have a constant coefficient. Furthermore, constructing matching rates for the various grants is a very tricky matter. Indeed, in general, many of the variables in the paper are new and have rather uncertain properties.

The reliance on distributed lags in the model raises still more issues. To a degree, I share the consensus view that where there are distributed lags, there is trouble. In this paper, the problem is especially serious, since the lag distribution is imposed on a set of four equations that are bound by several constraints and that involve strongly correlated variables.

Given all the pitfalls, Gramlich and Galper did a reasonably sensible job. They used ordinary least squares to get some feel for the distributed lags in each equation, and then essentially imposed the lags a priori when they estimated the equations together. They also made a number of simplifying, but necessary, assumptions, as in their weighting scheme and in their estimation of all equations in first-difference form. I should mention, however, that a more elegant estimation technique relevant to this empirical work has been developed; it arises out of econometric applications of consumer demand theory. The technique has been applied in the work of Barten and Theil, among others, and as it involves fewer assumptions than does the estimation procedure used in the paper, it might be worth trying in the present situation.

In the underlying theoretical model, the authors view the bulk of expenditures, except for those associated with the matching of categorical grants, as discretionary. This view assumes that decision makers have the ability to reconsider completely their expenditures each period. I am not sure how it would be done, but it would be desirable to incorporate the fact that, once a program is started, it is not easy to turn off. Consequently, some of the expenditures that the authors label as discretionary may really be somewhat predetermined. One footnote in the paper indicates that they 
considered this problem on the tax side, but it also deserves some analysis on the expenditure side.

To summarize, the time series results are sensitive to specification. Since the standard errors are hard to compute, the reliability of the point estimates cannot be accurately assessed. One important implication-or at least indication-of the time series results is that the relative price variables have only a negligible influence. Variations in the matching percentages of grants do not seem to affect the stimulative impact that is imparted to state and local government spending. The cross-sectional results are a bit more robust, and they do show some more important relative price effects. It is thus somewhat reassuring that the point estimates from the cross-sectional data are not dramatically different from the time series estimates.

On balance, Gramlich and Galper have given us a valuable first effort at sorting out some important issues. Moreover, their paper should stimulate further research to pin down some of the issues associated with both the cross-sectional and the time series analyses.

Martin McGuire: Hitherto, empirical work on state and local fiscal behavior has consisted largely of more or less ad hoc regression analyses. These studies have shown uniformly that the increase in state-local expenditures associated with an increase of one dollar in exogenous grant money from the federal government is much greater than the increase in state-local expenditures arising from an increment of one dollar in the endogenous income of the state or local community. The distinguishing characteristic of the Gramlich-Galper paper is that it attempts to explain such phenomena in terms of a classical utility-maximizing model (thereby carrying further previous work by Gramlich), and I applaud the effort.

One criticism, however, is that the functional form choosen for utility is inappropriate; rather than a quadratic utility function, the authors might better have chosen a logarithmic form. As derived in the appendix, the "equilibrium solution" equation to be estimated is linear in income and prices, and the well known Stone-Geary utility function generates just such a linear expenditure system, where every parameter has a well-understood and widely acknowledged interpretation. ${ }^{1}$ Why devise a linear expenditure system by dropping nonlinear terms from a quadratic utility function when

1. For example, see Arthur S. Goldberger, "Functional Form and Utility: A Review of Consumer Demand Theory" (University of Wisconsin, Social Systems Research Institute, October 1967; processed). 
a direct method is so readily at hand with the advantage that no such "simplifying" assumption is needed?

In this connection the authors have pointed out to me that a Stone-Geary linear expenditure system, if subject to aggregate consistency constraints on price and income parameters, does not produce maximum likelihood (ML) estimates. Of course neither does the Gramlich-Galper procedure of dropping terms produce such ML estimates of their quadratic utility function. ${ }^{2}$ The Stone-Geary system subjected to the above mentioned constraints is no longer linear in its parameters, although procedures (admittedly laborious) do exist for ML estimation of this Stone-Geary form. But assuming one is resigned to accepting some bias or inconsistency in the estimates, it seems preferable, when the option exists, to choose a utility function whose parameters are identifiable from the econometric estimates.

At a more detailed level the Gramlich-Galper utility model proposes two parameters, $\gamma_{1}$ and $\gamma_{2}$, to explain the "super-stimulativity" of grant money. The parameter $\gamma_{2}$ measures the relative weight of private incomes versus taxes in the preferences of local decision makers, in order to allow for the possibility that local officials might retain for local public spending a greater fraction of an exogenous unrestricted grant than they would tax an equal endogenous increase in private income. This hypothesized preference is intuitively appealing, and the empirical estimates of $\gamma_{2}$ are reasonable.

However, I have problems with $\gamma_{1}$, the "displacement effect" parameter. It implies that, when local officials receive categorical grants for a particular function, they do not reduce the previously planned level of their own expenditures on that same function by the same amount as they would if the grant were unrestricted; rather, the reduction due to categorical grants is only some fraction-approximately 0.35 , as empirically estimated-of the reduction due to unrestricted grants. The authors interpret this value of $\gamma_{1}$ to mean that the utility to local officials from these categorical grants is less than the utility they get from their own expenditures in the same category. The problem is, what does $\gamma_{1}$ on this interpretation explain? It says that categorical grants do not generate as much "utility" for local decision makers as do their own expenditures; but this is mere tautology. Why does that difference in utility exist? If the source of the difference is that man-

2. Richard W. Parks, "Maximum Likelihood Estimation of the Linear Expenditure System," Journal of the American Statistical Association, Vol. 66 (December 1971), pp. 900-03. 
dated and discretionary expenditures are for different goods, then another good should be added to the basic demand model.

Another comment relates to the distinction between discretionary and nondiscretionary expenditures of local governments. One reason for doubting this distinction is that some purposeful federal strategy may lie behind the allocation of categorical grants. The federal "supply" of grants may introduce some simultaneous causal relationship; for example, the federal government may purposely give big grants to poor states, or big grants with high matching rates to rich states. The possible presence of simultaneity should, therefore, be explored. More fundamentally, however, one questions the realism of dividing total expenditures into "discretionary" and "mandated" components, when the local government may have effective freedom to transfer "categorical" funds among categories.

\section{General Discussion}

William Brainard amplified Goldfeld's and McGuire's comments about the difficulties of defining discretionary expenditures. He felt that some types of spending work on a ratchet-for example, it is particularly difficult to cut educational expenditures. The levels are further pushed up over time by increasing salary demands and the changing age composition of teachers. The asymmetry of increases and decreases in the expenditure process may be fairly unimportant for growing communities, but critical to those that are stagnant or contracting.

Brainard also observed that the variable that measures the number of school children affects expenditure without a lag instead of working through the desired capital stock relationship. He thought it somewhat unusual that the treatment of this variable should differ from the lag structure of other variables.

Walter Heller was puzzled by the estimates of the long-run effects of revenue sharing. He felt intuitively that state and local governments, in the long run, would spend more than the 43 cents per dollar of shared federal revenues that the authors estimated as the ultimate response. In any case, he observed that, at the present time, revenue sharing appears to have become in part a substitute for categorical grants and an excuse for cutting general federal government expenditures as well. He remarked that this development represented a perversion of the rationale of revenue sharing, as 
formulated by Joseph Pechman and himself, which stresses the distinction between categorical aids in support of specific functions of national interest (because of externalities and so forth) and revenue sharing to cut down disparities among, and increase the capabilities of, state and local governments to support their own local functions. He recalled that he and Pechman had foreseen some substitution of shared funds for state and local taxes-a development not necessarily to be lamented, but had expected the magnitude of that substitution to be much smaller than that estimated by Gramlich and Galper. Harvey Galper noted that the results presented in the paper are quite consistent with the present political pressures for tax reduction. He pointed to specific announcements providing evidence that local governments, in particular, are using much of the shared revenues for projects previously funded by local taxes, while others have applied large parts of their federal moneys to debt retirement.

Edward Gramlich wanted to clarify the meaning of $\gamma_{1}$, the grant displacement parameter. Instead of measuring the relative expenditure reduction due to categorical grants, as McGuire said, it in fact measured the relative increase in total expenditures. If there were no displacement of categorical grants, $\gamma_{1}$ would be 0 and total expenditures would increase by the amount of mandated expenditures. If, on the other hand, displacement were complete, $\gamma_{1}$ would be unity and total expenditures would increase only as much as they would under a lump-sum transfer. The parameter $\gamma_{1}$, which is also the relative utility weight for mandated expenditures, then measures the exact location of the expenditure impact between these extremes.

In addition, Gramlich reiterated several reasons why the expenditure response to revenue sharing is likely to exceed the estimate of 43 cents per dollar. First, he noted, the revenue-sharing law contains a tax-effort formula that penalizes states for reducing their taxes. Second, the money may be distributed in a fashion differing from past patterns. For example, to some extent revenue sharing will go to poor states that are likely to spend an especially large portion of the funds they receive. Finally, revenue sharing at this time is particularly visible; and localities may perceive that, to the extent they reduce taxes in response to it, they will weaken their case for federal aid in the future.

Arthur Okun raised the issue of how the large surpluses of state-administered retirement funds are likely to affect aggregate demand. On a lifecycle or permanent-income view of the consumer, the pension saving would be offset by reductions of private saving. On other views, however, 
the funds would exert a drag on the economy. Alan Greenspan and Thomas Juster cited both cross-sectional and time series findings that private saving rates are actually positively correlated with funded retirement saving. Hendrik Houthakker speculated that this empirical relationship may reflect the transformation of the family structure; since parents are no longer supported by their children, they must rely not only on pension funds but also on increased personal saving as sources for their retirement years. But Juster argued that the cross-sectional results could not be explained by changes in the family structure over time. People with pension coverage save at least as much in nonpension forms as those without coverage; presumably, the need for retirement financing cannot be very different between the two groups.

In a comment related to the general state of state and local finances, Heller noted that an unusual coincidence of forces is basically responsible for the large state and local surpluses recently observed. These governments are simultaneously receiving newly shared federal funds, enjoying the current economic expansion, and reaping additional funds from newly increased tax rates legislated in the previous years of adversity. In view of this situation, Heller expected that the surpluses will dwindle. 